\title{
REVIEW
}

\section{ETMR: a tumor entity in its infancy}

\author{
Sander Lambo ${ }^{1,2} \cdot$ Katja von Hoff $^{4} \cdot$ Andrey Korshunov ${ }^{5,6} \cdot$ Stefan M. Pfister ${ }^{1,2,7} \cdot$ Marcel Kool $^{1,2,3}$
}

Received: 16 April 2020 / Revised: 4 June 2020 / Accepted: 18 June 2020 / Published online: 29 June 2020

(c) The Author(s) 2020

\begin{abstract}
Embryonal tumor with Multilayered Rosettes (ETMR) is a relatively rare but typically deadly type of brain tumor that occurs mostly in infants. Since the discovery of the characteristic chromosome 19 miRNA cluster (C19MC) amplification a decade ago, the methods for diagnosing this entity have improved and many new insights in the molecular landscape of ETMRs have been acquired. All ETMRs, despite their highly heterogeneous histology, are characterized by specific high expression of the RNA-binding protein LIN28A, which is, therefore, often used as a diagnostic marker for these tumors. ETMRs have few recurrent genetic aberrations, mainly affecting the miRNA pathway and including amplification of $C 19 M C$ (embryonal tumor with multilayered rosettes, $C 19 M C$-altered) and mutually exclusive biallelic DICER1 mutations of which the first hit is typically inherited through the germline (embryonal tumor with multilayered rosettes, DICERI-altered). Identification of downstream pathways affected by the deregulated miRNA machinery has led to several proposed potential therapeutical vulnerabilities including targeting the WNT, SHH, or mTOR pathways, MYCN or chromosomal instability. However, despite those findings, treatment outcomes have only marginally improved, since the initial description of this tumor entity. Many patients do not survive longer than a year after diagnosis and the 5-year overall survival rate is still lower than $30 \%$. Thus, there is an urgent need to translate the new insights in ETMR biology into more effective treatments. Here, we present an overview of clinical and molecular characteristics of ETMRs and the current progress on potential targeted therapies.
\end{abstract}

\section{Diagnosis of ETMRs}

Marcel Kool

m.kool@kitz-heidelberg.de

1 Hopp Children's Cancer Center (KiTZ), Heidelberg, Germany

2 Division of Pediatric Neurooncology, German Cancer Research Center (DKFZ), German Cancer Consortium (DKTK), Heidelberg, Germany

3 Princess Máxima Center for Pediatric Oncology, Utrecht, The Netherlands

4 Department of Pediatric Oncology/Hematology, Charite University Medicine, Berlin, Germany

5 Department of Neuropathology, Heidelberg University Hospital, Heidelberg, Germany

6 Clinical Cooperation Unit Neuropathology, German Cancer Research Center (DKFZ), Heidelberg, Germany

7 Department of Pediatric Oncology, Hematology and Immunology, University Hospital Heidelberg, Heidelberg, Germany
Embryonal tumor with Multilayered Rosettes (ETMR) is an aggressive, WHO-grade IV, brain tumor that occurs predominantly in infants under the age of 3 years [77, 124]. ETMRs were only recognized as a distinct entity in recent years and since the tumors are clinically highly heterogeneous in terms of location and histology, the disease has not been extensively studied [87]. Previously, ETMRs were classified under the umbrella of primitive neuroectodermal tumors of the central nervous system (CNS-PNETs) [88] and based on morphological patterns different histological variants were recognized, termed Embryonal Tumor with Abundant Neuropil and True Rosettes (ETANTR) [32], Ependymoblastoma (EBL) and Medulloepithelioma (MEPL) [88, 89]. However, both DNA methylation profiling and transcriptome analysis has clearly demonstrated that ETANTRs, EBLs, and MEPLs, all belong to the same molecular entity, collectively named ETMR, and which has been included in the WHO classification of CNS tumors since 2016 [77, 87].

Even though the histological patterns in ETMRs are diverse, there are characteristic features commonly observed in all ETMRs (Fig. 1). These features include large areas of 

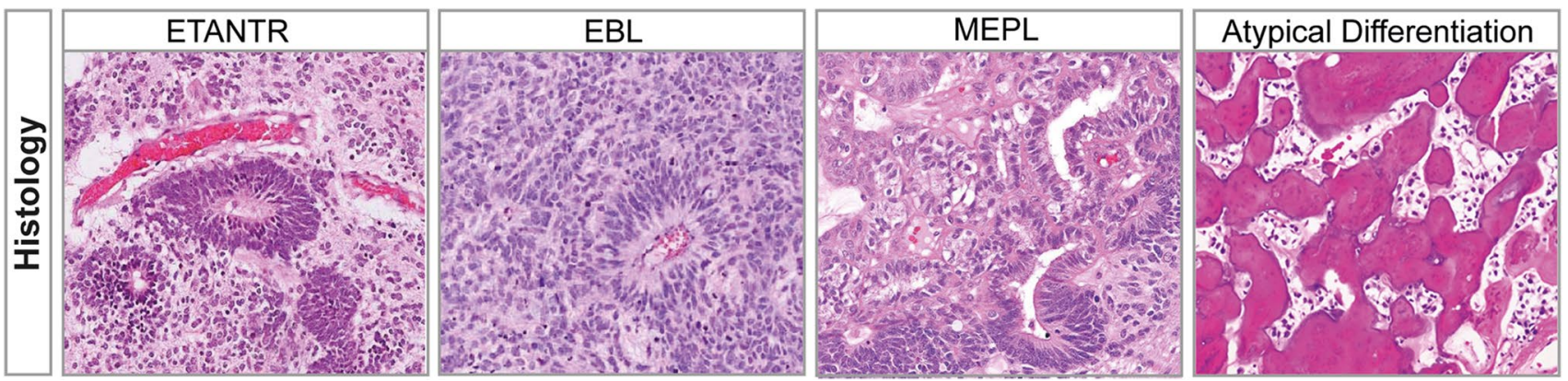

Fig. 1 Histology of ETMRs. Each panel shows diverse histological variants of ETMRs with the last panel showing an example of an atypical osteoid differentiation pattern in an ETMR [105]

neuropil, which contains a mixture of unmyelinated axons, dendrites and glial cells, and rosette structures consisting of multilayered mitotically active layers of neuroepithelial cells growing around a lumen $[32,43]$. ETMRs with ETANTR histology have large areas of neuropil with dense clusters of small cells that form rosettes, while ETMRs with EBL histology have an overall lower neuropil content but feature large sheets or clusters of poorly differentiated rosettes [32, 77]. MEPL histology is relatively rare but presents as tubular structures resembling the primitive neural tube, and tumors show low levels of neuropil [17]. ETMRs also occasionally present with structures that are atypical for the entity. For instance, there have been reports that ETMRs show a pineoblastoma-like histology and the histology of ETANTR tumors has also been confused with CNS neuroblastoma in the past $[43,80,124,126]$. Furthermore, there have been reports describing rare instances of divergent differentiation patterns in ETMRs, including osteoid, myeloid, epithelial, mesenchmyal or muscular differentiation $[1,17,105,129]$.

\section{Molecular diagnosis of ETMRs}

Because ETMRs show diverse patterns of histology, the diagnosis currently relies heavily on the identification of molecular characteristics. The first molecular characteristic, described in 2009, was amplification of the $19 \mathrm{q} 13.42$ locus that houses one of the largest microRNA clusters in the human genome named $C 19 M C[75,83,110]$. C19MC amplification is now considered as the genetic hallmark of ETMRs, present in $~ 90 \%$ of all ETMRs regardless their histology (Embryonal tumor with multilayered rosettes, C19MC-altered) [80]. The amplification can be identified using fluorescence in situ hybridization (FISH) or copy number profiling with either SNP arrays, DNA methylation arrays or next generation sequencing (NGS) approaches [75, 80]. In 2012, a second molecular characteristic was identified, as it was shown that all ETMRs, regardless of histological variant, stain highly positive for the marker LIN28A, even though this expression is restricted to rosette forming cells [76]. This marker is very useful for the identification of ETMRs, since the widespread LIN28A positivity as seen in ETMRs is very rarely seen in other brain tumor entities, which are either completely negative or only show some focal positivity $[76,114,124]$. Other less specific markers include the expression of nestin and vimentin in rosette forming cells, which lack expression of neuronal and glial cell markers [32, 43]. Such markers, including synapthophysin (SYP), neurofilamentprotein (NFP), and neuronal nuclei (NeuN) [17], are more expressed in the neuropil that may also contain rare populations of cells positive for astrocyte markers such as glial fibrillary acidic protein (GFAP) [87]. Nevertheless, with the development of new molecular methods to diagnose ETMRs it also became clear that not all LIN28A positive tumors that histologically resemble ETMRs have the C19MC amplicon [77, 124]. This affects $\sim 10 \%$ of all cases and even though the C19MC amplification, the genetic hallmark of the disease, is absent in those tumors we recently have shown with DNA methylation profiling and transcriptome analyses that these tumors $(C 19 M C-)$ are still molecularly similar to ETMRs having the $C 19 M C$ amplification $(C 19 M C+)$ [80]. Moreover, we have shown that these $C 19 M C$ - ETMRs frequently have biallelic DICER1 mutations (Embryonal tumors with multilayered rosettes, DICERI-altered) [80].

Currently, the WHO classification of histologically diagnosed MEPLs is still ambiguous as MEPLs with C19MC amplification are classified as ETMR, but MEPLs that lack the $C 19 M C$ amplification are listed separately as medulloepithelioma [89]. However, when clustering those tumors based on gene expression or DNA methylation profiling they were not found to be molecularly distinct from ETMRs $[80,124]$. Furthermore, there are also MEPLs that occur in the eye, named intraocular medulloepithelioma (IO-MEPL), which histologically resemble ETMRs and are positive for LIN28A staining but lack amplification of the C19MC locus [62]. However, in contrast to C19MC-ETMRs those tumors were found to be molecularly distinct based on DNA 
methylation profiling. In addition, IO-MEPLs can occur in older patients and overall have a more favorable outcome. Interestingly, IO-MEPLs also frequently harbor DICERI mutations, but currently it is unclear to what extend IOMEPLs differ from ETMRs [74].

\section{Tumor location}

The location of the primary tumor in the central nervous system (CNS) is also heterogeneous. Nearly all tumors reside in the brain, with approximately $70 \%$ occurring in supratentorial regions and $30 \%$ in infratentorial regions [43, $56,77]$ and while there are reports of ETMRs occurring in the spine, those cases are rare [56, 136] (Fig. 2). There is no direct correlation between histological variants and location of the tumor; however, a trend was observed for infratentorial occurrence of $C 19 M C$ - ETMRs, since these tumors often reside near the brainstem [80]. It is not clear whether this may reflect a different cell of origin as the tumors do not seem to separate based on DNA methylation or transcriptome profiling [80].

ETMRs mostly present as large and well demarcated tumors. Using magnetic resonance imaging (MRI), the tumors generally show a heterogeneous signal with frequent diffusion restriction, cystic components, as well as intratumoral hemorrhage [102]. Compared to other CNSembryonal tumors, the imaging characteristics of ETMRs are similar but the tumor size is overall larger with a mean tumor volume of $115 \mathrm{~cm}^{3}$ often spanning multiple lobes [61, 103]. The tumors frequently show very aggressive behavior and rapid growth, even during intensive treatment. Most commonly, tumors progress or recur locally yet distant leptomeningeal metastases may occur, and very rarely extracranial relapses have been observed [77, 119].

\section{Epidemiology}

Reliable epidemiological data that focus on ETMR are not yet available. However, CNS-embryonal tumors, which were previously subsumed within the group of tumors termed CNS-primitive neuroectodermal tumors (CNS-PNET), are diagnosed in roughly 1 per 700,000 children aged $0-4$ years [106]. While ETMRs may likely represent a relevant proportion of these tumors in infancy, it has been shown that, historically, frequent misdiagnosis occurred among patients diagnosed with CNS-PNETs [126]. Therefore, molecularly guided specification of diagnosis is needed to reliably determine the incidence of ETMR. The majority of ETMR patients is diagnosed at a very young age, since only $8 \%$ of all patients is over 3 years at diagnosis [77]. Initially, in small series there was a minor gender bias reported with a male to female ratio of roughly 1:1.1 [43, 124]; however, in larger cohorts this bias cannot be confirmed and the incidence seems to be equally balanced between males and females [80] (Fig. 2).

\section{Treatment and management}

Presenting symptoms are similar to other malignant brain tumors that occur at a very young age, and are based on the initial location, the size of the tumor, or secondary obstruction of cerebrospinal fluid circulation. Beside symptoms of raised intracranial pressure, paresis, seizures, visual impairments, ataxia, and torticollis may occur [43, 56]. Due to the aggressive nature of the disease, tumors may acutely present as large tumors with short symptomatic interval that may lead to a poor pre- and postoperative status with neurological impairment [92].

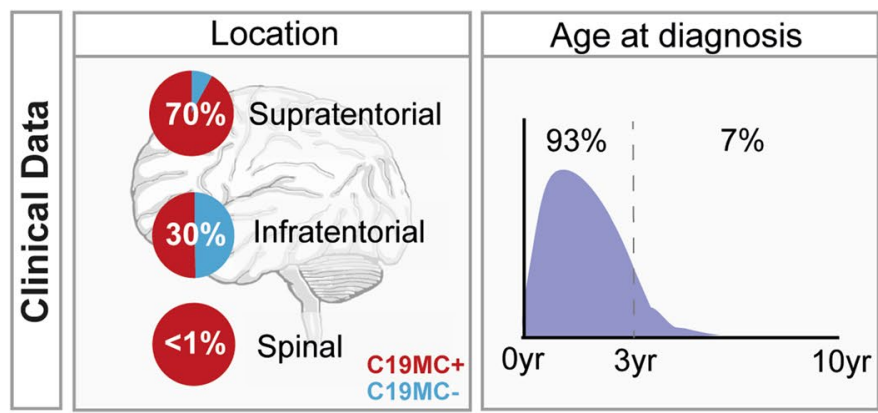

Fig. 2 Clinical characteristics of ETMRs. The first panel shows the distribution of ETMRs throughout the brain divided by the presence of $C 19 M C$ amplification, indicating that $C 19 M C-$ ETMRs are more often located infratentorially. The second and third panel show the age and gender distribution of ETMR patients. The few data that is available for $C 19 M C$ - ETMR suggests that there is no difference in age or gender distribution with $C 19 M C+$ ETMRs, which is the rea-
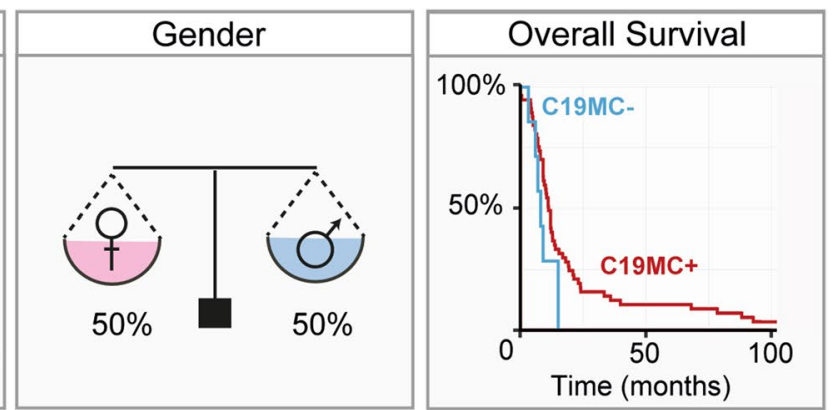

son why they are not visualized separately. The fourth panel shows the overall survival of ETMRs. There is a slight trend that C19MCETMR patients may do worse, but the difference with the $C 19 M C+$ ETMRs is not significant. C19MC+ denotes tumors having C19MC amplifications, $C 19 M C-$ denotes tumors lacking $C 19 M C$ amplifications 
Complete resection is often attempted for patients with localized disease, but the prognostic value of a complete resection as first surgical attempt still needs to be clarified. Similar to other malignant CNS tumors occurring at a very young age, gross total resection may be associated to a survival advantage. Nevertheless, surgery of a large tumor at this young age is associated with a high risk for perioperative complications and certain tumor locations preclude complete resection, in particular tumors residing in or near the brainstem [131]. Interestingly, there have been patients reported, for whom a second resection was performed after application of chemotherapy treatment, which led to long-term survival suggesting a possible benefit of secondary resections [3].

Due to the rarity of the disease, no tumor-specific treatment strategy using chemotherapy has been prospectively evaluated for ETMR patients so far. Current treatment strategies are based on prospective trials that enrolled CNSPNETs and other high-risk CNS-embryonal tumors and evaluated the effectivity of a combined induction chemotherapy and consolidation with high dose chemotherapy followed by autologous stem cell rescue. These strategies contain different combinations of drugs such as Etoposide, Cyclophosphamide, Vincristine, Methotrexate, Cisplatin, Carboplatin, and Thiotepa. Within these trials, improved survival compared to historic controls was reported for patients with CNS-PNET after increased dose intensity treatment, yet there is no data on whether these strategies are effective for ETMRs specifically [25, 33, 38].

Irradiation of ETMR patients is mostly not attempted, since there is no standard treatment protocol for young children that combines craniospinal irradiation with chemotherapy. Preclusion of craniospinal or local irradiation is mainly due to toxicity and associated risk for leptomeningeal spread, as observed in medulloblastoma [6]. Treatment protocols that combine craniospinal irradiation and chemotherapy have been evaluated for ETMR patients, even though these studies only included older patients, which are rare $[42,59]$. Despite the associated risks, a survival benefit has been suggested in a retrospective ETMR cohort and a prospective CNS-PNET cohort, likely containing ETMR patients [5, 56]. Also, when evaluating all published cases of surviving ETMR patients, the majority has received irradiation within the treatment course [63]. Nevertheless, the effectivity of frontline irradiation and effectivity of local irradiation for disease control remains to be evaluated in large prospective ETMR specific cohorts.

\section{Survival and prognosis}

Despite intensive and multimodal treatment, the reported outcome is still poor with 5-year overall survival rates between 0 and 30\% (Fig. 2). Many patients show aggressive progression of disease, which often is refractory to treatment and only single patients have been described that could effectively be salvaged upon relapse. However, there have also been reports on long-term survivors $[17,31,32,42$, $43,56,77,79,92,124]$. While so far outcome cannot be predicted by disease presentation or treatment factors due to the limited size of the cohorts, the reported data suggest a positive prognostic role for absence of metastases, complete resection and the application of dose-intense chemotherapy and/or irradiation. Still, there are patients fulfilling all positive criteria who develop early relapse and succumb to disease, while on the other hand, the few reported survivors include patients with initial metastatic presentation, incomplete resection and non-irradiated patients $[42,56]$. Interestingly, neuronal differentiation observed spontaneously or post-treatment seems to be associated with disease stabilization of variable duration and may represent another favorable prognostic factor $[3,31,79]$. Thus far, the histological variant and presence of (specific) copy number aberrations do not seem to be prognostic factors [77], but it is still unclear whether absence or presence of C19MC amplifications, size of the tumor, location of the tumor or age of diagnosis may influence outcome.

The reported data strongly suggest that the currently applied regimens do not offer effective disease control for the majority of the patients. On the other hand, the variability in the course of the disease gives room for hope that the aggressiveness of the tumor may be overcome by introduction of molecularly informed, specific drug combinations.

\section{Genetic aberrations in ETMR}

\section{C19MC}

Around $90 \%$ of all patients diagnosed with an ETMR have an amplification at $19 \mathrm{q} 13.42$ involving the miRNA cluster C19MC, which is thought to be the main driver of the tumor $[75,83,110]$. The roughly $100 \mathrm{~kb}$ long miRNA cluster C19MC possibly encodes 62 functional miRNAs; however, the exact number of functional miRNAs is unknown due to poor conservation of the cluster [11].

miRNAs are small non-coding RNAs that can be transcribed from separate promotors or processed from long RNA molecules [29, 71]. Functional miRNAs are formed by cleaving RNA molecules, which possibly contain multiple primary miRNAs (pri-miRNA), by a complex of DiGeorge syndrome chromosomal region 8 (DGCR8) and DROSHA [30, 48]. The cleaved products or precursor miRNAs (pre-miRNAs) are then exported out of the nucleus by a complex of exportin-5 (XPO5) and RAS-related nuclear protein (RAN) [30, 104], and subsequently further cleaved by a complex of DICER1 and trans-activation response 
RNA-binding protein (TRBP) in the cytosol $[13,39]$. The resulting 22 bp RNA molecules are the mature miRNAs, which are then loaded onto argonaute (AGO) to form the RNA-induced silencing complex (RISC) [137]. Formation of the RISC allows miRNAs to bind to mRNAs and is generally involved in regulating the abundance of proteins post-transcriptionally, either by inhibiting translation or by destabilization and degradation of an mRNA transcript [58]. However, there are also reports that miRNAs can regulate transcription directly $[85,111]$ or they may form interactions such as the formation of a scaffold that lead to increased protein abundance rather than a reduction (Fig. 3a) $[60,132]$.
It is challenging to predict the canonical targets of miRNAs, since the specificity of miRNAs is determined by the "seed" sequence: a small sequence of $6-8$ bases [78]. These sequences most commonly bind within the 3' UTR of a gene, but even when restricted to those regions it still results in hundreds to thousands of predicted sites for each miRNA [22]. This is particularly challenging for C19MC, since many individual miRNAs encoded in the cluster have distinct "seed" sequences which further increases the number of potential downstream targets $[11,78]$.

Validation of possible targets of $C 19 M C$ is difficult, since the cluster only exists in higher primates and is known to
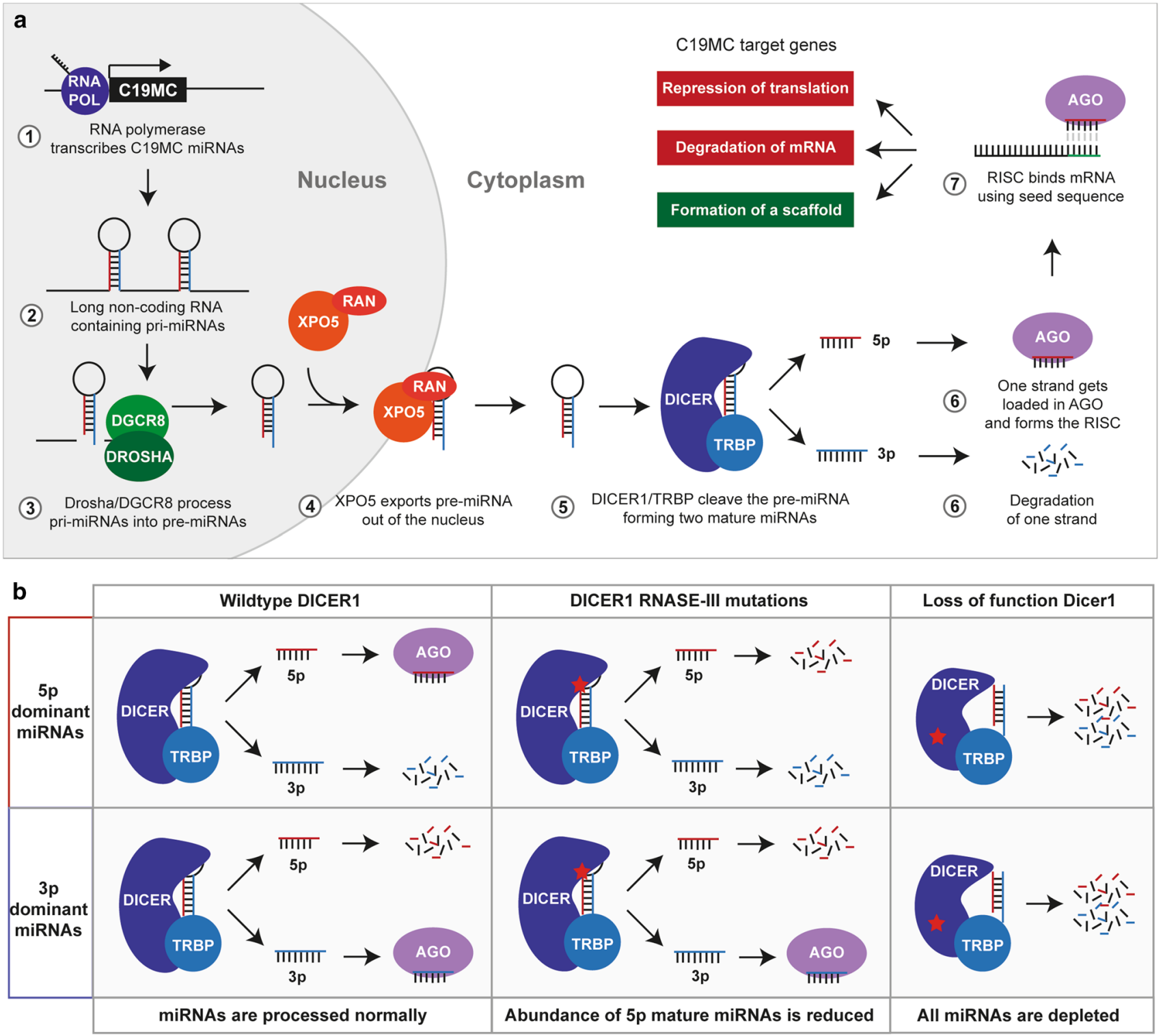

Fig. 3 miRNA processing in ETMRs. a Overview of miRNA processing and maturation using the C19MC miRNA cluster as an example. The effects on $C 19 M C$ target genes are colored based on the result on mRNA translation, green showing an increase and red a decrease in translation. The processing steps shown in this Figure are applicable to all miRNAs and not exclusive to C19MC. b Overview of different scenarios that mutations in DICER1 have on the abundance of $3 p$ and $5 p$ forms of mature miRNAs 
have an expression pattern that is restricted to early neural stem cells and the placenta under normal circumstances $[11,81]$. The cluster is imprinted and only expressed on the paternal allele when it is active, but in most cells both alleles are epigenetically silenced $[9,101]$. In ETMRs, expression of the $C 19 M C$ cluster is likely driven by a translocation and fusion that places the Tweety Family Member 1 (TTYHI) gene upstream of the miRNA cluster, followed by amplification of the region [73]. Even though the majority of $C 19 M C+$ cases have a translocation and fusion with TTYHI, other fusion partners, including $M Y O 9 B$ in a $C 19 M C$ - case and MIRLET7BHG in a C19MC+ case, have been observed. It is not clear whether TTYH1 plays a role in ETMRs, since apart from encoding a chloride anion channel and being expressed in brain, eye, testis and ovary, the function of the TTYH1 protein is currently not well understood $[49,125]$. Possibly TTYH1 plays a role in the differentiation of neural stem cells during brain development [70, 143], where TTYH1 is mainly expressed in neural stem cells, neurons and astrocytes [141]. The cell of origin of ETMRs is currently not known, but there are indications that ETMRs resemble a broad spectrum of developmental stages ranging from neural stem cells and early radial glia to a more differentiated lineage such as astrocytes and neurons based on histology [32, 43, 77], expressed markers [76, 98, 124], and single cell RNA sequencing [64]. It was proposed that loss of TTYHI expression during development can lead to loss of C19MC expression [64]; however, it remains to be elucidated how this loss in expression can occur.

Despite restricted expression patterns in normal tissue [11, 81], elevated C19MC expression has been observed in several other cancers including triple negative breast cancer [65], hepatocellular carcinoma [7, 36], testicular germ cell tumors [35], parathyroid tumors [130], multiple myeloma [12], and mesenchymal hamartoma of the liver [66]. Expression of $C 19 M C$ was in most studies associated to hypomethylation of $C 19 M C$ both at the cluster itself and the upstream region, suggesting that lack of epigenetic silencing can reactivate the cluster $[12,36,65,130]$. Expression of C19MC is also often associated with DNA copy number aberrations of the region, similar to what is seen in ETMRs, as multiple myeloma and triple negative breast cancer show copy number gain $[12,65]$, while parathyroid carcinoma and hepatocellular carcinoma show amplification of the cluster [7, 130]. Mesenchymal hamartoma of the liver seems to show a different mechanism to activate the cluster: the maternal allele is lost, while the paternal allele, which is actively transcribed, is gained [66]. Nevertheless, a fusion as observed in ETMR has not been reported so far in other tumors.

The function of $C 19 M C$ in other tumors remains elusive, even though $C 19 M C$ expression is generally correlated with a poor outcome and larger tumor size [7, 35, 130]. Nevertheless, it has been shown that several individual C19MC
miRNAs can increase the efficiency of reprogramming during the generation of induced pluripotent stem cells by inhibiting the epithelial to mesenchymal transition $[96,99]$. A similar role was observed in the placenta, where C19MC miRNAs prevent trophoblast differentiation through inhibition of WNT signaling [147]. Furthermore, it has been shown that $C 19 M C$ miRNAs can also induce cell proliferation and invasion in trophoblast cells [144]. Similar observations of increased proliferation and invasion were also made in multiple tumor types including breast cancer [57], hepatocellular carcinoma [36], and ETMR [26], suggesting a role for $C 19 M C$ in metastasis and tumor growth. However, the role of C19MC miRNAs in tumorigenesis is still ambiguous, since several individual miRNAs have also shown to inhibit proliferation and migration [55, 67]. Furthermore, for C19MC miRNAs, having the same "seed sequence" both tumor suppressive and oncogenic functions have been reported [34], suggesting that the downstream mechanisms of $C 19 M C$ are highly context dependent.

\section{MIR17HG}

ETMRs also rarely have amplification of another miRNA cluster on chromosome 13, the miR-17-92 (MIR17HG) cluster, which was reported in three patients. In two of these patients, the amplification was detected in ETMRs without C19MC amplification, while in one case, it co-occurred with $C 19 M C$ amplification [80]. Similar to $C 19 M C$, the MIR 17HG cluster has been associated to increased proliferation and invasiveness in multiple cancers and is the first described oncogenic miRNA cluster [94]. Interestingly, the MIR17HG miRNA cluster is co-expressed with C19MC during placental development [46] and has several "seed" sequences that are identical to mature miRNAs encoded in C19MC [78, 91], suggesting that both clusters may be coregulated and potentially have overlapping functions and targets.

\section{DICER1 mutations}

The second most common genetic event found in ETMRs are biallelic mutations affecting DICERI, present in approximately $5 \%$ of all ETMR patients and occurring exclusively in tumors lacking C19MC or MIR17HG amplifications [80, 129]. Mutations affecting DICERI show a pattern that is typically found in tumors associated to the DICER1 predisposition syndrome, having one inactivating germline mutation and one somatic mutation in the RNase III domain [16, 28]. The RNase III domain is involved in cleaving the double stranded precursor miRNAs that forms a hairpin after processing by DGCR8 and DROSHA. This results in either the $3 p$ or $5 p$ arm to be loaded consistently in AGO, while the other is degraded (Fig. 3a) [68]. Based on the structure of 
DICER1, the catalytic site, where the pre-miRNA is cleaved is mainly formed by the residues S1344 in the RNase IIIa domain, responsible for cleaving the $3 p$ arm, and E1705, D1709 and E1813 in the RNase IIIb domain, responsible for cleaving the $5 p$ arm [133], which are also the residues that are most often mutated in ETMR and other cancers [86, 133]. Mutations at the catalytic domain, irrespective of the affected domain, ultimately leads to an increased loading of $3 p$ forms of mature miRNAs into RISC as the improperly processed $5 p$ form is degraded (Fig. 3b) [2, 133]. In general, this bias in loading $3 p$ miRNAs leads to distinct sites that are targeted as the "seed" sequence differs between the $3 p$ and $5 p$ form [78]. This was shown to mainly affect miRNA clusters that predominantly load $5 \mathrm{p}$ forms such as the let 7 miRNA cluster, while clusters that predominantly load $3 p$ miRNAs are less affected (Fig. 3b) [133].

Cancers associated to the DICERI predisposition syndrome, both benign and malignant, primarily have biallelic loss of function mutations and mutations affecting an RNASE III domain of DICER1 (reviewed in [28]). However, there are also tumors such as Wilms tumor or pineoblastoma that recurrently have mutations leading to a complete loss of function of DICER 1 or that have mutations in other members of the miRNA processing pathway such as mutations in DROSHA and DGCR8 [82, 84, 109, 128, 135]. These tumors rarely have mutations in the RNase IIIa or RNase IIIb domain of DICER1, suggesting that a general lack of miRNA processing, rather than biased loading of $3 p$ miRNAs, is the driving mechanism in the majority of these tumors [113]. Interestingly, two cases initially histologically diagnosed as pineoblastoma and harbouring RNase IIIb domain mutations in DICERI were by DNA methylation profiling reclassified as ETMRs [84]. Together with earlier findings that ETMRs could present with a pineoblastomalike histology this opens the possibility that the type of aberration affecting DICERI could influence what type of tumor develops. Mesenchymal hamartomas of the liver also show DICERI mutations affecting the RNase IIIb domain, which are, interestingly, again mutually exclusive with C19MC aberrations [4], in line to what is observed in ETMRs [80]. ETMRs were found to be molecularly similar regardless of C19MC amplification, suggesting that DICERI mutations affecting the RNase III domains and C19MC may have common downstream mechanisms. This could potentially explain why other members of the miRNA processing pathway were not found to be mutated in ETMRs [80], since this possibly affects different downstream mechanisms.

\section{Other recurrent aberrations in ETMRs}

Our recent genomic analyses using whole genome and whole exome DNA sequencing have not revealed many other recurrent coding mutations in ETMRs. The most common aberrations include mutations affecting exon 3 of CTNNB1, which leads to activation of the WNT signaling pathway by preventing the degradation of the $\beta$-catenin protein [142], identified in $10 \%$ of all patients $[44,80,98]$, and homozygous or hemizygous TP53 mutations, occurring in 7\% of all patients [80]. Both were identified in $C 19 M C+$ as well as in C19MC-ETMRs.

ETMRs recurrently have DNA copy-number aberrations such as gain of chromosome 2 , reported in approximately $70 \%$ of all cases $[43,77,80,110]$. Other chromosome arms recurrently gained or lost include 1q (gained in $\sim 25 \%$ ), $6 \mathrm{q}$ (lost in 20\%), 17q (gained in $\sim 10 \%$ ), chromosome $7 \mathrm{p}$ and $7 \mathrm{q}$ (gained in $\sim 10 \%$ ), 3q (gained in $\sim 10 \%$ ) and 11q (gained in $\sim 10 \%)[77,80,120]$. Copy number aberrations were often found to be paired with focal chromosomal instability, mainly around $C 19 M C$, in some cases resulting in more than 100 breakpoints that lead to TTYH1-C19MC fusion and amplification [73, 80]. Chromosomal instability in ETMRs is not directly associated to TP53 mutations as seen in other cancers [115], since only a small subset of cases with high levels of chromosomal instability have TP53 mutations, suggesting that other mechanisms may play a role in this, such as R-loops (as further discussed below), which have shown to be abundantly present in ETMRs [80]. An overview of genetic aberrations found in ETMRs is given in Fig. 4.

\section{Active pathways in ETMR}

\section{The LIN28A/let-7 pathway}

Apart from mutations affecting the miRNA pathway, all ETMRs have a characteristic high expression of the RNAbinding protein LIN28A [76, 124], known for its role in regulating the let-7 miRNA family [52]. It has been shown that LIN28A can inhibit maturation of let-7 miRNAs by binding to the terminal loop of the let-7 pre-miRNA and recruiting $3^{\prime}$ terminal uridylyl transferase 4 (TUT4) [47, 53]. This leads to polyuridylation, preventing further miRNA processing and eventually leading to degradation of the pre-miRNA, which subsequently leads to reduced levels of mature let7 miRNAs in the cell (Fig. 5) [47, 53]. Generally speaking, miRNAs belonging to the let-7 miRNA family have tumor suppressive functions, while LIN28A and the paralog LIN28B, commonly overexpressed in a diverse spectrum of cancers $[8,149]$, are considered to be oncogenes. Indeed overexpression of LIN28A or LIN28B is sufficient to induce tumors like neuroblastomas or Wilms tumors in mice [95, 118], but thus far there are no reports showing that they can also induce brain tumors [139]. However, it is clear that LIN28A is important in ETMRs as cell viability is reduced when expression of the gene is silenced [98]. 


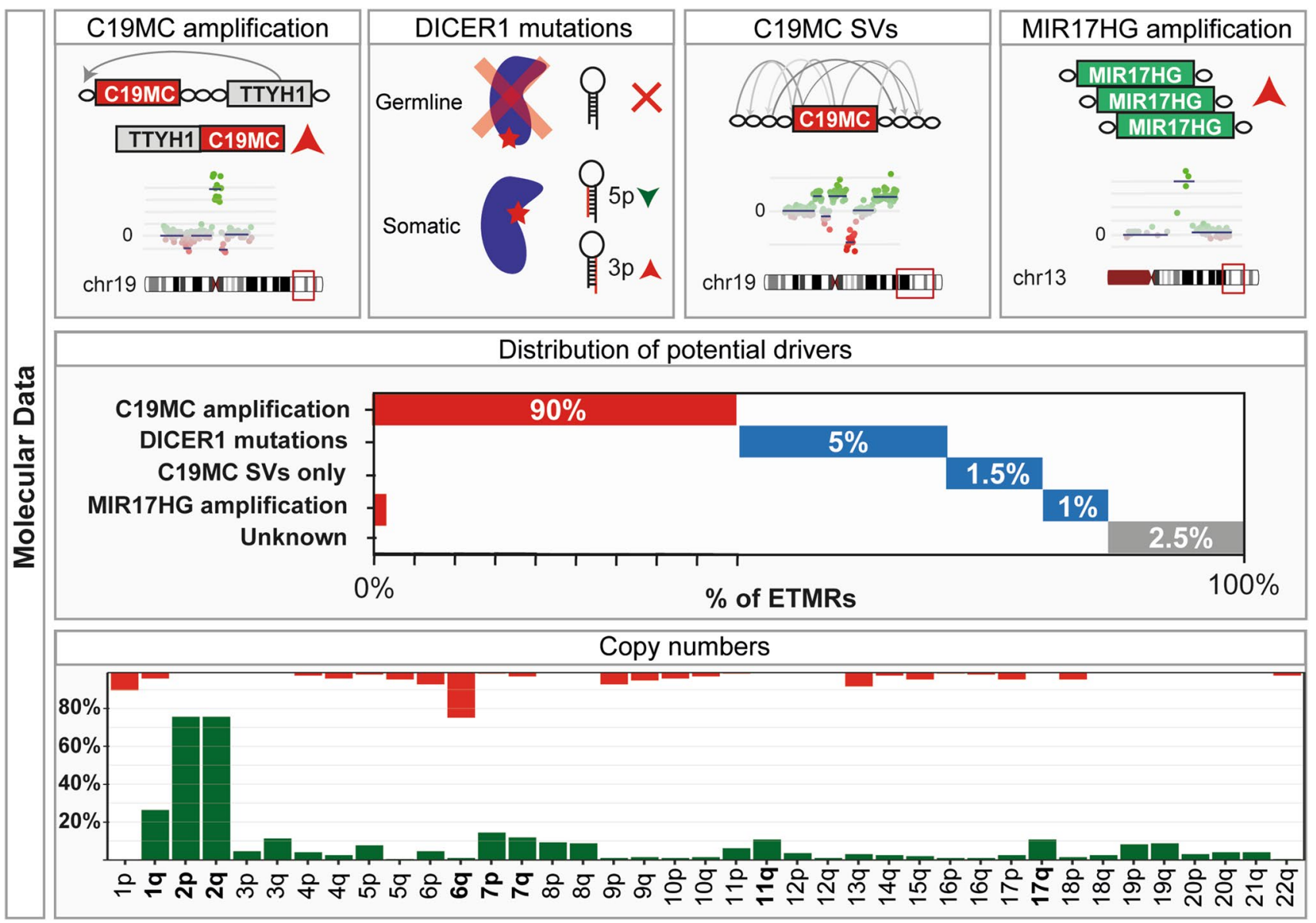

Fig. 4 Aberrations found in ETMRs. Figure showing the four identified potential drivers of ETMRs schematically in the top row, the distribution of these aberrations in the second row and the distribution of gains and losses in the last row. In the distribution of poten- tial drivers colors denote $\mathrm{C} 19 \mathrm{MC}+(\mathrm{red})$ and $\mathrm{C} 19 \mathrm{MC}-$ (blue). In the distribution of copy number aberrations green denotes a gain and red denotes a loss. No significant differences in copy number changes have been observed between C19MC + and C19MC - [80]

\section{LIN28A-driven pathways in ETMR}

LIN28A is highly expressed in embryonic stem cells and known to be involved in retaining stemness. Retaining an undifferentiated state may be required for ETMRs as well, since ETMRs consist of populations resembling neural stem cells, radial glial cells and more differentiated cells $[64,98]$. Since the more undifferentiated cells have higher expression of genes associated to proliferation and have a propensity to grow out upon relapse, they likely play a pivotal role in ETMRs $[64,77,80]$. Currently, it is not clear how undifferentiated cells are retained in ETMRs; however, there are reports suggesting that LIN28A related mechanisms potentially regulate this process. For instance, high mobility group A2 (HMGA2), a gene that is highly expressed in embryonic stem cells and involved in the regulation of self-renewal, is a well-documented let-7 target, and therefore, upregulated when let-7 miRNAs are repressed through LIN28A [93, 100]. HMGA 2 can bind DNA and modify the chromatin state leading to upregulation of multiple pathways involved in oncogenesis including the mTOR pathway, TGF- $\beta$ pathway, RAS pathway and cell cycle progression among others [134]. These pathways downstream of HMGA2 and let-7, such as the mTOR pathway, are indeed also suggested to play a role in ETMRs as shown by upregulation of the downstream factors IGF2BP1 and IGF2BP2 [15, 76, 123, 150]. HMGA2 also leads to upregulation of NOTCH effectors, including HES5, which play an important role in cell fate decisions of neural stem cells and regulating differentiation timing [107]. Interestingly, both HMGA2 and HES5 are highly upregulated in ETMRs [76] and may possibly underlie the suppression of differentiation in ETMRs.

Other pathways active and suggested to play a central role are the WNT and SHH pathway, which may also contribute to the stemness seen in ETMRs [80, 98]. This is supported by the observation that $C T N N B 1$ mutations are recurrently observed in ETMRs and a subset of ETMRs show nuclear accumulation of CTNNB1, which 


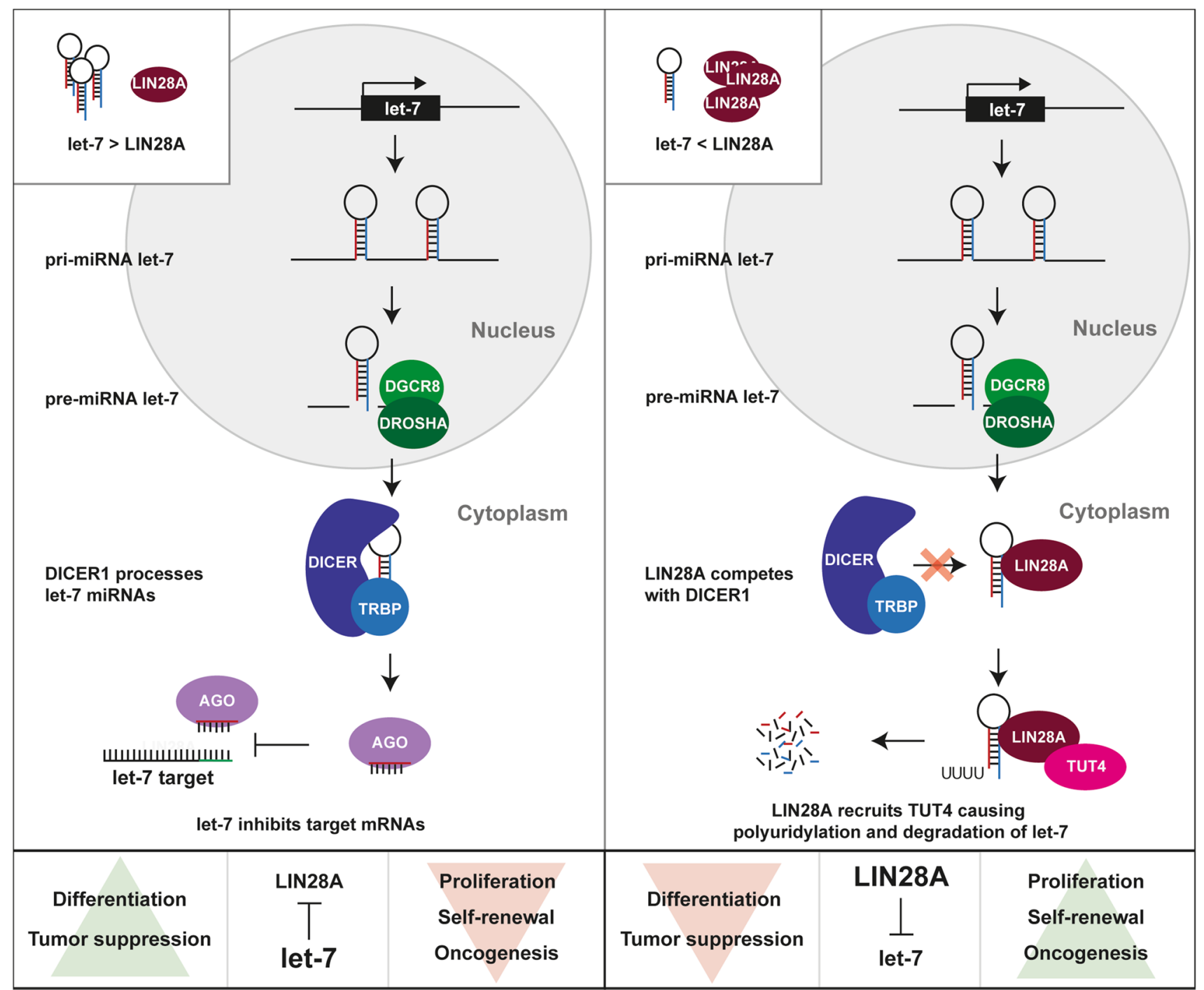

Fig. 5 Regulation of let-7 by LIN28A. Schematic overview of miRNA processing of let-7 and repression of let-7 targets in the absence (left) or presence (right) of LIN28A. ETMRs have low

expression of let-7 miRNAs and high expression of LIN28A as is shown in the right overview. This pathway is exclusive to let-7 miRNAs and does not apply to all miRNAs

is associated with aberrant activation of the WNT pathway $[44,80]$. Mutations in SHH pathway genes also occur in ETMRs, but were not found to be recurrent $[80,98]$. Furthermore, it has been shown that introducing activating $C T N N B 1$ and smoothened (SMO) mutations in GFAP expressing cells leads to tumor-like structures in the forebrain of mice that histologically resemble ETMRs [98]. In the same study, it was demonstrated that the WNT pathway can be activated downstream of LIN28A through a decrease in let-7a miRNAs. However, it is unclear which let-7a target modulates the WNT signaling in ETMRs and whether this inhibition is direct or indirect [98]. Possibly, this occurs through upregulation of HMGA2 as well, since several reports have shown a functional link between HMGA2 and WNT signaling [121, 140].
Another major pathway active in ETMRs is the v-myc myelocytomatosis viral related oncogene, neuroblastoma derived (MYCN) pathway. MYCN mRNA expression is upregulated in most ETMRs as compared to other pediatric brain tumors, most likely because the gene resides on chromosome 2, which is gained in $70 \%$ of all ETMRs $[43,77]$. However, focal amplifications of $M Y C N$ have never been observed in ETMRs [80, 120]. Expression of $M Y C N$ can also indirectly be regulated by LIN28A as multiple reports have shown that lack of let-7 miRNAs leads to upregulation of MYCN $[95,112,118]$. This can occur either directly, since let-7 can target MYCN, or through activation of ras-related nuclear protein (RAN), which leads to increased transcription and phosphorylation of aurora kinase A (AURKA) and subsequent upregulation of MYCN, as shown in 
neuroblastoma [118]. Recently, it has been described that ETMRs could indeed be MYCN driven, based on a core regulatory circuit derived from super enhancers, which may explain why ETMRs are overall very aggressive [120].

\section{Downstream effects of C19MC and DICER1 mutations on the LIN28A/let-7 pathway}

The question remains; however, how mutually exclusive genetic aberrations such as $C 19 M C$ amplification or DICER1 mutations lead to a common downstream mechanism, since the tumors were found to be molecularly similar. A first indication is that both expression of $C 19 M C$ and presence of DICERI mutations have been shown to increase the efficiency of reprogramming stem cells $[72,96,99,138]$ and lead to a delay in differentiation in either the placenta, as shown for C19MC [147], or globally, in patients affected by the DICER1 predisposition syndrome [72]. Since reprogramming is also regulated by LIN28A and considering the mutual exclusivity of C19MC amplifications and DICERI mutations it is attractive to speculate that both recurrent aberrations lead to depletion of let-7 miRNAs and subsequent upregulation of let-7 targets.

Currently, a direct link between C19MC and LIN28A has not been proven but there is evidence that $C 19 M C$ may affect LIN28A indirectly, for instance by downregulating Tristetraprolin (TTP), a protein that degrades LIN28A [69, 120]. Other factors may also be involved, since many different miRNAs have been shown to target LIN28 directly or indirectly, including let-7 miRNAs, which generate a negative feedback loop [8, 145], suggesting that a deregulated miRNA processing in general could also underlie changes in the regulation of LIN28A. Furthermore, LIN28 is regulated by pluripotency factors including octamer-binding transcription factor 4 (OCT4), SRY-Box Transcription Factor 2 (SOX2) and NANOG amongst others [18, 24], and considering ETMRs to resemble early neural stem cells the upregulation of LIN28A may also be a secondary event [32, 43, 77].

DICER1 mutations may also affect LIN28A/let7 signaling. Based on expression profiling in ovarian Sertoli-Leydigcell tumors, Wilms tumors and Uterine Corpus Endometrial Carcinoma with DICER1 RNase IIIb mutations, let-7 targets were found among the most significantly upregulated genes compared to other tumors of the same type that lacked DICER1 RNase IIIb mutations [113, 133, 138]. This included factors such as HMGA2 and IGF2BP2 among others, and by re-expressing let-7 miRNAs the phenotype resulting from DICER1 mutations could be partially rescued [133, 138]. Downstream of DICER1 mutations affecting the RNase IIIb domain, an increase of WNT and MYCN signaling was detected as well, suggesting that DICER1 mutations have similar downstream effects as LIN28A expression [113]. Ultimately, there are many pathways that act downstream of LIN28A and likely drive the tumor (illustrated in Fig. 6), providing new opportunities for rationally designed targeted therapies.

\section{miRNA processing and chromosomal instability}

\section{The role of miRNA processing factors in DNA repair}

Next to its role in regulating oncogenic pathways it is known that the miRNA processing pathway can also be involved in the DNA damage response (DDR). This is illustrated by an impressive number of miRNAs that are differentially regulated after activation of the DNA damage checkpoint [51, 148]. Interestingly, ETMRs recurrently have chromosomal instability and aberrations affecting miRNAs or miRNA processing, while somatic mutations in factors that canonically regulate the DDR, such as TP53, are relatively rare [80].

Furthermore, members of the miRNA processing machinery, in particular DICER1, have also been associated with DDR resulting from replication stress [21, 127]. The importance of DICER1 in preventing replication stress is illustrated by the finding that embryonic lethality occurs when DICER1 is deleted partially due to increased DNA damage in rapidly proliferative tissues, such as stem cells [14, 127]. Moreover, it has been shown that cells can be sensitized to induced replication stress with a knock down of DICER1 [127]. It is currently unknown how DICERI loss leads to DNA damage upon replication stress; however, it has been postulated that an increase in the level of R-loops, observed after lack of DICER1 function, might play a role $[21,80]$. R-loops are structures that form upon stalling of RNA polymerase II and result in a single strand of DNA that hybridizes with a single strand of RNA while displacing the non-template strand of DNA, which remains single stranded. Formation of R-loops can cause or result from a collision of transcription and replication and when R-loops are not properly resolved this can lead to DNA damage and chromosomal instability [41, 116].

One mechanism by which the miRNA processing machinery prevents formation of R-loops is through the regulation of transcription termination. In yeast, it was shown that both dcr1 or ago mutants have an increased read-through of transcription at transcription termination sites that causes replication forks to stall at peri-centromeric repeats [146] and other regions of the genome [21]. This was later shown to cause R-loops to form, likely based on a failure to remove Pol II from the DNA by dcr1 [21]. In mice, it was shown that Dicer1, Ago1 and Ago2 bind at sites of R-loops to facilitate the placement of repressive chromatin marks over termination sites [122], suggesting that Dicer1, Ago1 and Ago2 can prevent chromosomal instability by preventing R-loop 


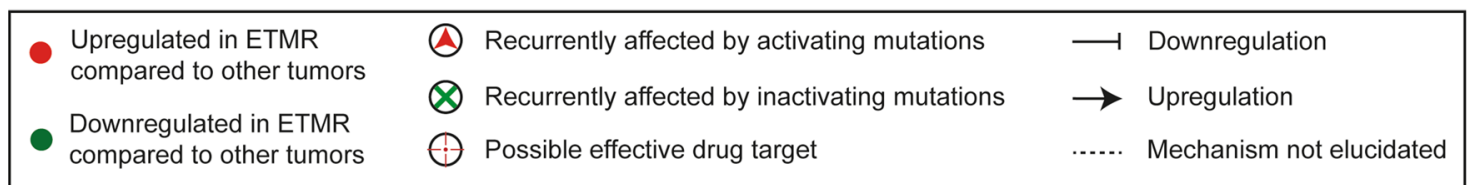

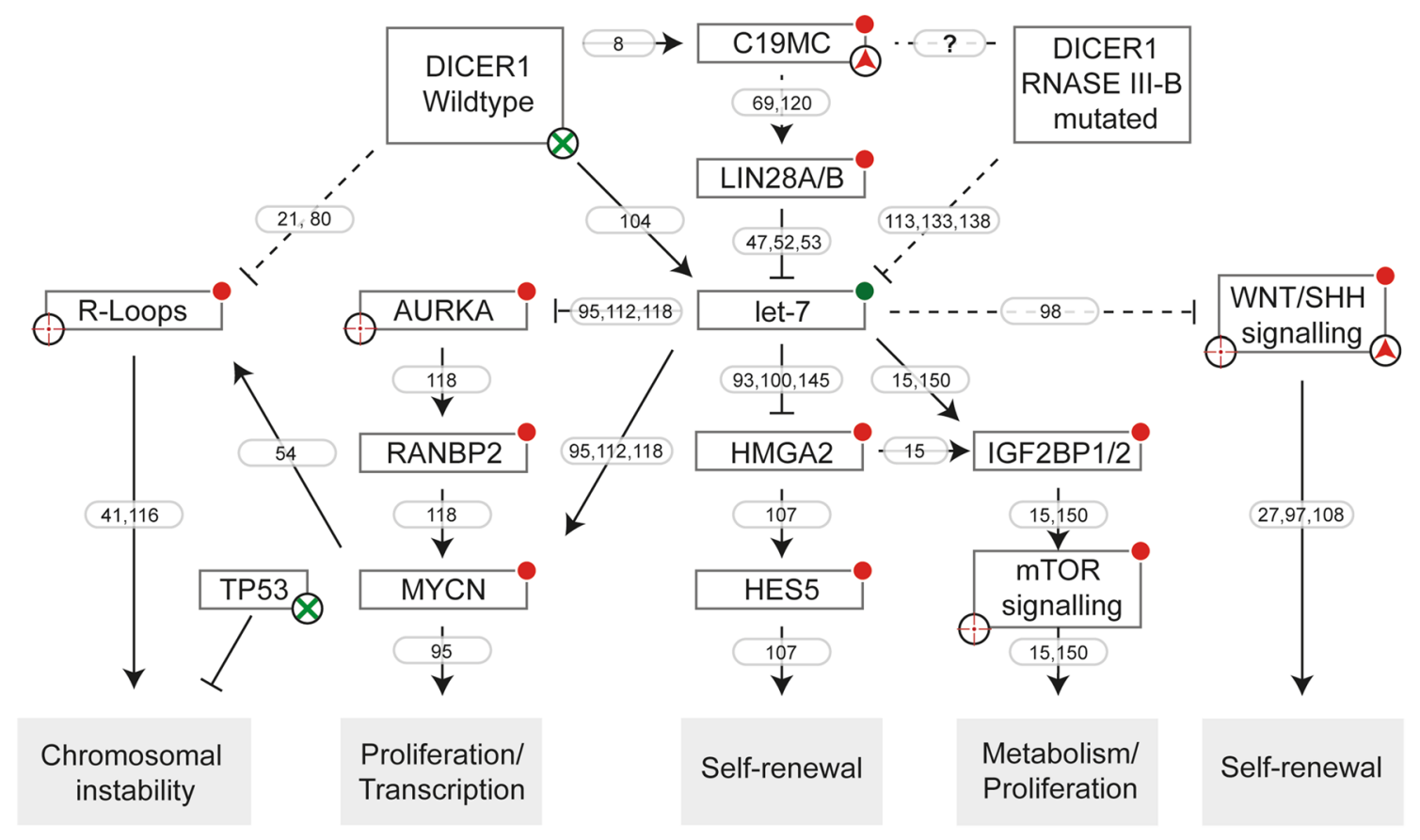

Fig. 6 Active pathways in ETMR. Figure illustrating genes and pathways active in ETMR downstream of DICER1 (mutations) and C19MC and that have been investigated in ETMRs

formation. Indeed, mouse embryonic stem cells (mESC) having a knockout of Dicerl were found to have increased levels of R-loops and DNA damage compared to wildtype mESCs [80]. Currently, it is not clear whether DICER1 mutations affecting the RNase IIIb domain exert a similar function on the formation of R-loops. However, the recruitment of DNA repair factors to sites of DNA damage also relies on phosphorylation of the S1728 and S1852 residues, which affect the RNase IIIb domain and dsRNA binding domain, respectively [19]. This occurs independently of the miRNA biogenesis pathway suggesting that the RNase IIIb domain is also directly involved in maintaining genome stability [37].

The role of C19MC in chromosomal instability is still unclear, but since factors other than DICER1 such as DGCR8, DROSHA, AGO1 and AGO2 are also involved in DNA repair, a general deregulation of miRNA processing may underlie the chromosomal instability in tumors lacking DICER1 mutations [40]. Indeed, overexpression of miRNAs can lead to saturation of the miRNA processing machinery and subsequent DNA damage [10, 45]. Furthermore, $C 19 M C$ may also target the DNA repair machinery directly, since expression of C19MC in HEK293 cells leads to downregulation of the response to UV radiation and the p53 pathway, which both require the miRNA machinery to repair lesions [20, 23, 96].

\section{Novel therapeutic leads}

Currently, conventional treatment regimens provide only a limited benefit for ETMR patients, warranting the development of novel therapeutic options including rationally designed targeted therapies. Due to the limited number of well-characterized preclinical models for ETMRs it remains challenging to develop and prioritize novel therapeutic options. A screening approach using the BT183 ETMR cell line [123] with a library of 73 different drugs showed that the cell line had increased sensitivity to IGF1R inhibitors, PI3K inhibitors, mTOR inhibitors and topoisomerase inhibitors [123]. Another independent drug screen on the same cell line was performed using 35 different compounds, which confirmed the effectiveness mTOR inhibitors and topoisomerase inhibitors, and resulted in the identification of further compounds such as Actinomycin D, anthracyclines, polo-like kinase inhibitors, aurora kinase inhibitors and the 
epigenetic drugs decitabine and panobinostat amongst other possibly effective compounds [117]. Activity of several drugs including Topotecan, Volasertib and Actinomycin D was confirmed in vivo using an orthopic xenograft model and combinations with topoisomerase inhibitors and doxorubicin led to a further increase of survival of the mice, yet no long-term cures or disease control [117]. In accordance with the pre-clinical activity of doxorubicin, and actinomycin D, a small number of ETMR patients were also treated according to regimens given to patients with atypical teratoid rhabdoid tumors (ATRT) [50, 117]; however, it remains to be shown that this provides additional benefit.

Recent studies have also proposed other rationally designed treatments based on active pathways rather than a screening approach. One study proposed that SHH inhibitors could be effective in treating ETMRs, based on the capability of forming tumors with ETMR-like histology using activation of the WNT and SHH pathways and a general upregulation of the SHH pathway in ETMRs [98]. Indeed, arsenic trioxide (ATO), which inhibits the SHH pathway, was able to slow the growth of ETMR cells in vitro and in vivo [98]. However, ATO has shown to inhibit other targets as well which lead to differentiation. Therefore, the reduced growth may have been caused by inducing differentiation rather than inhibiting the SHH pathway specifically. Another study proposed to target super enhancers using the bromodomain inhibitor JQ1, since ETMRs were shown to have a MYCN driven super enhancer network and also C19MC is likely driven by super enhancers. This has shown to be effective in cell lines but has yet to be tested in vivo [120]. Finally, it was proposed that the chromosomal instability in ETMRs can be used as a therapeutic target based on the presence of high levels of R-loops [80]. Previously, we have shown that R-loops and cell death increased in the BT183 ETMR cell line when treated with topoisomerase inhibitors, which could be further augmented using a combination of PARP inhibitors and topoisomerase inhibitors. Nevertheless, also this potential therapy still needs to be validated in vivo, and is additionally depending on whether a good brain penetrance of the drugs can be achieved [80].

\section{Future perspectives}

Since the discovery of the $C 19 M C$ aberration more than a decade ago, there has been an improved understanding of ETMR biology, better diagnostic tools, identification of most driving aberrations and possible downstream targets. In addition, possible vulnerabilities for preclinical and eventually clinical evaluation have been identified. Nevertheless, the survival of ETMR patients has only marginally improved due to the lack of prospective trials and trials evaluating molecularly informed specific drug combinations.
Furthermore, due to the limited number of cases and paucity of long-term survivors, the determination of prognostic factors that lead to a favorable outcome is currently not possible. In addition, there is a lack of rigorous pre-clinical testing of drug targets, since there are only few preclinical ETMR models available. This shortage in preclinical models currently impedes the progress towards better therapeutic options and needs to be resolved before moving towards comprehensive clinical evaluation. A better understanding of ETMR biology is required as well; although LIN28 regulated pathways could be promising to target, the connection between DICER1 mutations, C19MC amplification and LIN28 expression remains ambiguous.

Nevertheless, the identification of driving events, for instance DICERI mutations, and downstream pathways may lead to the development of a more comprehensive set of models that will allow further evaluation of the suggested specific treatments and may possibly identify novel strategies. For instance, it may be possible to target LIN28A directly as was shown to be effective in neuroblastoma [90] or to target epigenetic marks which have been implicated in ETMR pathogenesis [73]. Despite the rarity of the disease, its frequency may increase with improved diagnostics, including molecular classification, as patients were often misdiagnosed in the past [126]. An increased number of identified patients and intense international collaboration will hopefully soon lead to more well-characterized preclinical models and the international set-up of ETMR specific prospective trials. Nevertheless, available data suggest that introduction of preclinically informed specific treatments are on the horizon and with rationally designed targeted therapies and comprehensive pre-clinical testing, it may be possible to eventually improve the outcome of these young patients.

Acknowledgments Open Access funding provided by Projekt DEAL.

Open Access This article is licensed under a Creative Commons Attribution 4.0 International License, which permits use, sharing, adaptation, distribution and reproduction in any medium or format, as long as you give appropriate credit to the original author(s) and the source, provide a link to the Creative Commons licence, and indicate if changes were made. The images or other third party material in this article are included in the article's Creative Commons licence, unless indicated otherwise in a credit line to the material. If material is not included in the article's Creative Commons licence and your intended use is not permitted by statutory regulation or exceeds the permitted use, you will need to obtain permission directly from the copyright holder. To view a copy of this licence, visit http://creativecommons.org/licenses/by/4.0/.

\section{References}

1. Al-Hussaini M, Abuirmeileh N, Swaidan M, Al-Jumaily U, Rajjal H, Musharbash A et al (2011) Embryonal tumor with abundant 
neuropil and true rosettes: a report of three cases of a rare tumor, with an unusual case showing rhabdomyoblastic and melanocytic differentiation. Neuropathology 31:620-625. https://doi.org/10. 1111/j.1440-1789.2011.01213.x

2. Anglesio MS, Wang Y, Yang W, Senz J, Wan A, Heravi-Moussavi A et al (2013) Cancer-associated somatic DICER1 hotspot mutations cause defective miRNA processing and reverse-strand expression bias to predominantly mature $3 p$ strands through loss of 5p strand cleavage. J Pathol 229:400-409. https://doi. org/10.1002/path.4135

3. Antonelli M, Korshunov A, Mastronuzzi A, Diomedi Camassei F, Carai A, Colafati GS et al (2015) Long-term survival in a case of ETANTR with histological features of neuronal maturation after therapy. Virchows Arch 466:603-607. https://doi.org/10.1007/ s00428-015-1736-5

4. Apellaniz-Ruiz M, Segni M, Kettwig M, Gluer S, Pelletier D, Nguyen VH et al (2019) Mesenchymal Hamartoma of the Liver and DICER1 Syndrome. N Engl J Med 380:1834-1842. https:// doi.org/10.1056/NEJMoa1812169

5. Aridgides PD, Kang G, Mazewski C, Merchant TE (2019) Outcomes after radiation therapy for very young children with highrisk medulloblastoma or supratentorial primitive neuroectodermal tumor treated on COG ACNS0334. Int J Radiat Oncol Biol Phys 105:S109. https://doi.org/10.1016/j.ijrobp.2019.06.602

6. Ashley DM, Merchant TE, Strother D, Zhou T, Duffner P, Burger $P C$ et al (2012) Induction chemotherapy and conformal radiation therapy for very young children with nonmetastatic medulloblastoma: Children's Oncology Group study P9934. J Clin Oncol 30:3181-3186. https://doi.org/10.1200/JCO.2010.34.4341

7. Augello C, Vaira V, Caruso L, Destro A, Maggioni M, Park YN et al (2012) MicroRNA profiling of hepatocarcinogenesis identifies C19MC cluster as a novel prognostic biomarker in hepatocellular carcinoma. Liver Int 32:772-782. https://doi.org/10.11 11/j.1478-3231.2012.02795.x

8. Balzeau J, Menezes MR, Cao S, Hagan JP (2017) The LIN28/let-7 pathway in cancer. Front Genet 8:31. https://doi. org/10.3389/fgene.2017.00031

9. Bellemer C, Bortolin-Cavaille ML, Schmidt U, Jensen SM, Kjems J, Bertrand E et al (2012) Microprocessor dynamics and interactions at endogenous imprinted C19MC microRNA genes. J Cell Sci 125:2709-2720. https://doi.org/10.1242/jcs.100354

10. Bennasser Y, Chable-Bessia C, Triboulet R, Gibbings D, Gwizdek C, Dargemont C et al (2011) Competition for XPO5 binding between Dicer mRNA, pre-miRNA and viral RNA regulates human Dicer levels. Nat Struct Mol Biol 18:323-327. https://doi. org/10.1038/nsmb.1987

11. Bentwich I, Avniel A, Karov Y, Aharonov R, Gilad S, Barad O et al (2005) Identification of hundreds of conserved and nonconserved human microRNAs. Nat Genet 37:766-770. https://doi. org/10.1038/ng 1590

12. Berenstein R, Blau O, Nogai A, Waechter M, Slonova E, Schmidt-Hieber M et al (2015) Multiple myeloma cells alter the senescence phenotype of bone marrow mesenchymal stromal cells under participation of the DLK1-DIO3 genomic region. BMC Cancer 15:68. https://doi.org/10.1186/s12885-015-1078-3

13. Bernstein E, Caudy AA, Hammond SM, Hannon GJ (2001) Role for a bidentate ribonuclease in the initiation step of RNA interference. Nature 409:363-366. https://doi.org/10.1038/35053110

14. Bernstein E, Kim SY, Carmell MA, Murchison EP, Alcorn H, Li MZ et al (2003) Dicer is essential for mouse development. Nat Genet 35:215-217. https://doi.org/10.1038/ng1253

15. Brants JR, Ayoubi TA, Chada K, Marchal K, Van de Ven WJ, Petit MM (2004) Differential regulation of the insulin-like growth factor II mRNA-binding protein genes by architectural transcription factor HMGA2. FEBS Lett 569:277-283. https:// doi.org/10.1016/j.febslet.2004.05.075
16. Brenneman M, Field A, Yang J, Williams G, Doros L, Rossi C et al (2015) Temporal order of RNase IIIb and loss-of-function mutations during development determines phenotype in pleuropulmonary blastoma/DICER1 syndrome: a unique variant of the two-hit tumor suppression model. F1000res 4:214. https://doi. org/10.12688/f1000research.6746.2

17. Buccoliero AM, Castiglione F, Rossi Degl'Innocenti D, Franchi A, Paglierani M, Sanzo M et al (2010) Embryonal tumor with abundant neuropil and true rosettes: morphological, immunohistochemical, ultrastructural and molecular study of a case showing features of medulloepithelioma and areas of mesenchymal and epithelial differentiation. Neuropathology 30:84-91. https://doi. org/10.1111/j.1440-1789.2009.01040.x

18. Buganim Y, Faddah DA, Cheng AW, Itskovich E, Markoulaki S, Ganz K et al (2012) Single-cell expression analyses during cellular reprogramming reveal an early stochastic and a late hierarchic phase. Cell 150:1209-1222. https://doi. org/10.1016/j.cell.2012.08.023

19. Burger K, Schlackow M, Potts M, Hester S, Mohammed S, Gullerova M (2017) Nuclear phosphorylated Dicer processes double-stranded RNA in response to DNA damage. J Cell Biol 216:2373-2389. https://doi.org/10.1083/jcb.201612131

20. Calses PC, Dhillon KK, Tucker N, Chi Y, Huang JW, Kawasumi M et al (2017) DGCR8 mediates repair of UV-induced DNA damage independently of RNA processing. Cell Rep 19:162-174. https://doi.org/10.1016/j.celrep.2017.03.021

21. Castel SE, Ren J, Bhattacharjee S, Chang AY, Sanchez M, Valbuena A et al (2014) Dicer promotes transcription termination at sites of replication stress to maintain genome stability. Cell 159:572-583. https://doi.org/10.1016/j.cell.2014.09.031

22. Chi SW, Zang JB, Mele A, Darnell RB (2009) Argonaute HITS-CLIP decodes microRNA-mRNA interaction maps. Nature 460:479-486. https://doi.org/10.1038/nature08170

23. Chitale S, Richly H (2018) DICER- and MMSET-catalyzed H4K20me2 recruits the nucleotide excision repair factor XPA to DNA damage sites. J Cell Biol 217:527-540. https://doi. org/10.1083/jcb.201704028

24. Cimadamore F, Amador-Arjona A, Chen C, Huang CT, Terskikh AV (2013) SOX2-LIN28/let-7 pathway regulates proliferation and neurogenesis in neural precursors. Proc Natl Acad Sci USA 110:E3017-E3026. https://doi.org/10.1073/ pnas. 1220176110

25. Cohen BH, Geyer JR, Miller DC, Curran JG, Zhou T, Holmes E et al (2015) Pilot study of intensive chemotherapy with peripheral hematopoietic cell support for children less than 3 years of age with malignant brain tumors, the CCG-99703 phase I/II Study. A report from the Children's Oncology Group. Pediatr Neurol 53:31-46. https://doi.org/10.1016/j.pediatrneurol.2015.03.019

26. D'Asti E, Huang A, Kool M, Meehan B, Chan JA, Jabado N et al (2016) Tissue factor regulation by miR-520g in primitive neuronal brain tumor cells: a possible link between oncomirs and the vascular tumor microenvironment. Am J Pathol 186:446-459. https://doi.org/10.1016/j.ajpath.2015.10.020

27. Dave RK, Ellis T, Toumpas MC, Robson JP, Julian E, Adolphe $\mathrm{C}$ et al (2011) Sonic hedgehog and notch signaling can cooperate to regulate neurogenic divisions of neocortical progenitors. PLoS ONE 6:e14680. https://doi.org/10.1371/journal.pone.0014680

28. de Kock L, Priest JR, Foulkes WD, Alexandrescu S (2019) An update on the central nervous system manifestations of DICER1 syndrome. Acta Neuropathol. https://doi.org/10.1007/s0040 1-019-01997-y

29. de Rie D, Abugessaisa I, Alam T, Arner E, Arner P, Ashoor H et al (2017) An integrated expression atlas of miRNAs and their promoters in human and mouse. Nat Biotechnol 35:872-878. https://doi.org/10.1038/nbt.3947 
30. Denli AM, Tops BB, Plasterk RH, Ketting RF, Hannon GJ (2004) Processing of primary microRNAs by the Microprocessor complex. Nature 432:231-235. https://doi.org/10.1038/nature03049

31. Dunham C, Sugo E, Tobias V, Wills E, Perry A (2007) Embryonal tumor with abundant neuropil and true rosettes (ETANTR): report of a case with prominent neurocytic differentiation. J Neurooncol 84:91-98. https://doi.org/10.1007/s11060-007-9346-y

32. Eberhart CG, Brat DJ, Cohen KJ, Burger PC (2000) Pediatric neuroblastic brain tumors containing abundant neuropil and true rosettes. Pediatr Dev Pathol 3:346-352. https://doi.org/10.1007/ s100249910049

33. Fangusaro J, Finlay J, Sposto R, Ji L, Saly M, Zacharoulis S et al (2008) Intensive chemotherapy followed by consolidative myeloablative chemotherapy with autologous hematopoietic cell rescue (AuHCR) in young children with newly diagnosed supratentorial primitive neuroectodermal tumors (sPNETs): report of the head start I and II experience. Pediatr Blood Cancer 50:312-318. https://doi.org/10.1002/pbc.21307

34. Flor I, Bullerdiek J (2012) The dark side of a success story: microRNAs of the C19MC cluster in human tumours. J Pathol 227:270-274. https://doi.org/10.1002/path.4014

35. Flor I, Spiekermann M, Loning T, Dieckmann KP, Belge G, Bullerdiek J (2016) Expression of microRNAs of C19MC in different histological types of testicular germ cell tumour. Cancer Genom Proteom 13:281-289

36. Fornari F, Milazzo M, Chieco P, Negrini M, Marasco E, Capranico G et al (2012) In hepatocellular carcinoma miR519d is up-regulated by p53 and DNA hypomethylation and targets CDKN1A/p21, PTEN, AKT3 and TIMP2. J Pathol 227:275-285. https://doi.org/10.1002/path.3995

37. Francia S, Michelini F, Saxena A, Tang D, de Hoon M, Anelli V (2012) Site-specific DICER and DROSHA RNA products control the DNA-damage response. Nature 488:231-235. https ://doi.org/10.1038/nature11179

38. Friedrich C, von Bueren AO, von Hoff K, Gerber NU, Ottensmeier H, Deinlein F (2013) Treatment of young children with CNS-primitive neuroectodermal tumors/pineoblastomas in the prospective multicenter trial HIT 2000 using different chemotherapy regimens and radiotherapy. Neuro Oncol 15:224-234. https://doi.org/10.1093/neuonc/nos292

39. Fukunaga R, Han BW, Hung JH, Xu J, Weng Z, Zamore PD (2012) Dicer partner proteins tune the length of mature miRNAs in flies and mammals. Cell 151:912. https://doi. org/10.1016/j.cell.2012.10.029

40. Gao M, Wei W, Li MM, Wu YS, Ba Z, Jin KX et al (2014) Ago2 facilitates Rad51 recruitment and DNA double-strand break repair by homologous recombination. Cell Res 24:532541. https://doi.org/10.1038/cr.2014.36

41. Garcia-Muse T, Aguilera A (2019) R loops: from physiological to pathological roles. Cell 179:604-618. https://doi. org/10.1016/j.cell.2019.08.055

42. Gerber NU, von Hoff K, von Bueren AO, Treulieb W, Warmuth-Metz M, Pietsch T et al (2011) Outcome of 11 children with ependymoblastoma treated within the prospective HITtrials between 1991 and 2006. J Neurooncol 102:459-469. https://doi.org/10.1007/s11060-010-0347-x

43. Gessi M, Giangaspero F, Lauriola L, Gardiman M, Scheithauer BW, Halliday W et al (2009) Embryonal tumors with abundant neuropil and true rosettes: a distinctive CNS primitive neuroectodermal tumor. Am J Surg Pathol 33:211-217. https://doi. org/10.1097/PAS.0b013e318186235b

44. Gessi M, Zur Muehlen A, Lauriola L, Gardiman MP, Giangaspero F, Pietsch T (2011) TP53, beta-Catenin and c-myc/N-myc status in embryonal tumours with ependymoblastic rosettes. Neuropathol Appl Neurobiol 37:406-413. https://doi.org/10. 1111/j.1365-2990.2010.01151.x
45. Grimm D, Streetz KL, Jopling CL, Storm TA, Pandey K, Davis $\mathrm{CR}$ et al (2006) Fatality in mice due to oversaturation of cellular microRNA/short hairpin RNA pathways. Nature 441:537541. https://doi.org/10.1038/nature04791

46. Gu Y, Sun J, Groome LJ, Wang Y (2013) Differential miRNA expression profiles between the first and third trimester human placentas. Am J Physiol Endocrinol Metab 304:E836-843. https://doi.org/10.1152/ajpendo.00660.2012

47. Hagan JP, Piskounova E, Gregory RI (2009) Lin28 recruits the TUTase Zcchc11 to inhibit let-7 maturation in mouse embryonic stem cells. Nat Struct Mol Biol 16:1021-1025. https://doi. org/10.1038/nsmb.1676

48. Han J, Lee Y, Yeom KH, Kim YK, Jin H, Kim VN (2004) The Drosha-DGCR8 complex in primary microRNA processing. Genes Dev 18:3016-3027. https://doi.org/10.1101/gad.12625 04

49. Han YE, Kwon J, Won J, An H, Jang MW, Woo J et al (2019) Tweety-homolog (Ttyh) family encodes the pore-forming subunits of the swelling-dependent volume-regulated anion channel (VRACswell) in the brain. Exp Neurobiol 28:183-215. https:// doi.org/10.5607/en.2019.28.2.183

50. Hanson D, Chi S, Ziegler D (2019) MEDU-38. A case series of children with embryonal tumor with multilayer rosettes treated with a modified IRS-III chemotherapy backbone. Neuro-oncology 21:ii111. https://doi.org/10.1093/neuonc/noz036.196

51. He L, He X, Lim LP, de Stanchina E, Xuan Z, Liang Y et al (2007) A microRNA component of the p53 tumour suppressor network. Nature 447:1130-1134. https://doi.org/10.1038/natur e05939

52. Heo I, Joo C, Cho J, Ha M, Han J, Kim VN (2008) Lin28 mediates the terminal uridylation of let-7 precursor MicroRNA. Mol Cell 32:276-284. https://doi.org/10.1016/j.molcel.2008.09.014

53. Heo I, Joo C, Kim YK, Ha M, Yoon MJ, Cho J et al (2009) TUT4 in concert with Lin28 suppresses microRNA biogenesis through pre-microRNA uridylation. Cell 138:696-708. https:// doi.org/10.1016/j.cell.2009.08.002

54. Herold S, Kalb J, Buchel G, Ade CP, Baluapuri A, Xu J et al (2019) Recruitment of BRCA1 limits MYCN-driven accumulation of stalled RNA polymerase. Nature 567:545-549. https:// doi.org/10.1038/s41586-019-1030-9

55. Hong L, Ya-Wei L, Hai W, Qiang Z, Jun-Jie L, Huang A et al (2016) MiR-519a functions as a tumor suppressor in glioma by targeting the oncogenic STAT3 pathway. J Neurooncol 128:3545. https://doi.org/10.1007/s11060-016-2095-z

56. Horwitz M, Dufour C, Leblond P, Bourdeaut F, Faure-Conter C, Bertozzi AI et al (2016) Embryonal tumors with multilayered rosettes in children: the SFCE experience. Childs Nerv Syst 32:299-305. https://doi.org/10.1007/s00381-015-2920-2

57. Huang Q, Gumireddy K, Schrier M, le Sage C, Nagel R, Nair S et al (2008) The microRNAs miR-373 and miR-520c promote tumour invasion and metastasis. Nat Cell Biol 10:202-210. https ://doi.org/10.1038/ncb1681

58. Huntzinger E, Izaurralde E (2011) Gene silencing by microRNAs: contributions of translational repression and mRNA decay. Nat Rev Genet 12:99-110. https://doi.org/10.1038/nrg2936

59. Hwang EI, Kool M, Burger PC, Capper D, Chavez L, Brabetz $S$ et al (2018) Extensive molecular and clinical heterogeneity in patients with histologically diagnosed CNS-PNET treated as a single entity: a report from the Children's Oncology Group Randomized ACNS0332 trial. J Clin Oncol. https://doi.org/10.1200/ JCO.2017.76.4720

60. Ipsaro JJ, Joshua-Tor L (2015) From guide to target: molecular insights into eukaryotic RNA-interference machinery. Nat Struct Mol Biol 22:20-28. https://doi.org/10.1038/nsmb.2931

61. Jaju A, Hwang EI, Kool M, Capper D, Chavez L, Brabetz S et al (2019) MRI features of histologically diagnosed supratentorial 
primitive neuroectodermal tumors and pineoblastomas in correlation with molecular diagnoses and outcomes: a report from the Children's Oncology Group ACNS0332 trial. AJNR Am J Neuroradiol 40:1796-1803. https://doi.org/10.3174/ajnr.A6253

62. Jakobiec FA, Kool M, Stagner AM, Pfister SM, Eagle RC, Proia $\mathrm{AD}$ et al (2015) Intraocular medulloepitheliomas and embryonal tumors with multilayered rosettes of the brain: comparative roles of LIN28A and C19MC. Am J Ophthalmol 159(10651074):e1061. https://doi.org/10.1016/j.ajo.2015.03.002

63. Jaramillo S, Grosshans DR, Philip N, Varan A, Akyuz C, McAleer MF et al (2019) Radiation for ETMR: literature review and case series of patients treated with proton therapy. Clin Transl Radiat Oncol 15:31-37. https://doi.org/10.1016/j. ctro.2018.11.002

64. Jessa S, Blanchet-Cohen A, Krug B, Vladoiu M, Coutelier M, Faury D et al (2019) Stalled developmental programs at the root of pediatric brain tumors. Nat Genet 51:1702-1713. https ://doi.org/10.1038/s41588-019-0531-7

65. Jinesh GG, Flores ER, Brohl AS (2018) Chromosome 19 miRNA cluster and CEBPB expression specifically mark and potentially drive triple negative breast cancers. PLoS ONE 13:e0206008. https://doi.org/10.1371/journal.pone.0206008

66. Kapur RP, Berry JE, Tsuchiya KD, Opheim KE (2014) Activation of the chromosome 19q microRNA cluster in sporadic and androgenetic-biparental mosaicism-associated hepatic mesenchymal hamartoma. Pediatr Dev Pathol 17:75-84. https://doi. org/10.2350/13-12-1415-OA.1

67. Keklikoglou I, Koerner C, Schmidt C, Zhang JD, Heckmann D, Shavinskaya A et al (2012) MicroRNA-520/373 family functions as a tumor suppressor in estrogen receptor negative breast cancer by targeting NF-kappaB and TGF-beta signaling pathways. Oncogene 31:4150-4163. https://doi.org/10.1038/ onc.2011.571

68. Khvorova A, Reynolds A, Jayasena SD (2003) Functional siRNAs and miRNAs exhibit strand bias. Cell 115:209-216. https ://doi.org/10.1016/s0092-8674(03)00801-8

69. Kim CW, Vo MT, Kim HK, Lee HH, Yoon NA, Lee BJ et al (2012) Ectopic over-expression of tristetraprolin in human cancer cells promotes biogenesis of let-7 by down-regulation of Lin 28 . Nucleic Acids Res 40:3856-3869. https://doi.org/10.1093/nar/ gkr1302

70. Kim J, Han D, Byun SH, Kwon M, Cho JY, Pleasure SJ et al (2018) Ttyh1 regulates embryonic neural stem cell properties by enhancing the Notch signaling pathway. EMBO Rep. https://doi. org/10.15252/embr.201745472

71. Kim YK, Kim VN (2007) Processing of intronic microRNAs. EMBO J 26:775-783. https://doi.org/10.1038/sj.emboj.7601512

72. Klein SD, Martinez-Agosto JA (2019) Hotspot mutations in DICER 1 causing GLOW Syndrome-associated macrocephaly via modulation of specific microRNA populations results in activation of PI3K/ATK/mTOR signaling. Microrna. https://doi. org/10.2174/2211536608666190624114424

73. Kleinman CL, Gerges N, Papillon-Cavanagh S, Sin-Chan P, Pramatarova A, Quang DA et al (2014) Fusion of TTYH1 with the C19MC microRNA cluster drives expression of a brain-specific DNMT3B isoform in the embryonal brain tumor ETMR. Nat Genet 46:39-44. https://doi.org/10.1038/ng.2849

74. Korshunov A, Jakobiec FA, Eberhart CG, Hovestadt V, Capper D, Jones DT et al (2015) Comparative integrated molecular analysis of intraocular medulloepitheliomas and central nervous system embryonal tumors with multilayered rosettes confirms that they are distinct nosologic entities. Neuropathology 35:538544. https://doi.org/10.1111/neup.12227

75. Korshunov A, Remke M, Gessi M, Ryzhova M, Hielscher T, Witt $\mathrm{H}$ et al (2010) Focal genomic amplification at 19q13.42 comprises a powerful diagnostic marker for embryonal tumors with ependymoblastic rosettes. Acta Neuropathol 120:253-260. https://doi.org/10.1007/s00401-010-0688-8

76. Korshunov A, Ryzhova M, Jones DT, Northcott PA, van Sluis P, Volckmann R et al (2012) LIN28A immunoreactivity is a potent diagnostic marker of embryonal tumor with multilayered rosettes (ETMR). Acta Neuropathol 124:875-881. https://doi. org/10.1007/s00401-012-1068-3

77. Korshunov A, Sturm D, Ryzhova M, Hovestadt V, Gessi M, Jones DT et al (2014) Embryonal tumor with abundant neuropil and true rosettes (ETANTR), ependymoblastoma, and medulloepithelioma share molecular similarity and comprise a single clinicopathological entity. Acta Neuropathol 128:279-289. https:// doi.org/10.1007/s00401-013-1228-0

78. Kozomara A, Birgaoanu M, Griffiths-Jones S (2019) miRBase: from microRNA sequences to function. Nucleic Acids Res 47:D155-D162. https://doi.org/10.1093/nar/gky1141

79. Lafay-Cousin L, Hader W, Wei XC, Nordal R, Strother D, Hawkins $C$ et al (2014) Post-chemotherapy maturation in supratentorial primitive neuroectodermal tumors. Brain pathology (Zurich, Switzerland) 24:166-172. https://doi.org/10.1111/bpa.12089

80. Lambo S, Grobner SN, Rausch T, Waszak SM, Schmidt C, Gorthi A et al (2019) The molecular landscape of ETMR at diagnosis and relapse. Nature 576:274-280. https://doi.org/10.1038/s4158 6-019-1815-x

81. Landgraf P, Rusu M, Sheridan R, Sewer A, Iovino N, Aravin A et al (2007) A mammalian microRNA expression atlas based on small RNA library sequencing. Cell 129:1401-1414. https://doi. org/10.1016/j.cell.2007.04.040

82. Li BK, Vasiljevic A, Dufour C, Yao F, Ho BLB, Lu M et al (2020) Pineoblastoma segregates into molecular sub-groups with distinct clinico-pathologic features: a Rare Brain Tumor Consortium registry study. Acta Neuropathol 139:223-241. https://doi. org/10.1007/s00401-019-02111-y

83. Li M, Lee KF, Lu Y, Clarke I, Shih D, Eberhart C et al (2009) Frequent amplification of a chr19q13.41 microRNA polycistron in aggressive primitive neuroectodermal brain tumors. Cancer Cell 16:533-546. https://doi.org/10.1016/j.ccr.2009.10.025

84. Liu APY, Gudenas B, Lin T, Orr BA, Klimo P Jr, Kumar R et al (2019) Risk-adapted therapy and biological heterogeneity in pineoblastoma: integrated clinico-pathological analysis from the prospective, multi-center SJMB03 and SJYC07 trials. Acta Neuropathol. https://doi.org/10.1007/s00401-019-02106-9

85. Liu M, Roth A, Yu M, Morris R, Bersani F, Rivera MN et al (2013) The IGF2 intronic miR-483 selectively enhances transcription from IGF2 fetal promoters and enhances tumorigenesis. Genes Dev 27:2543-2548. https://doi.org/10.1101/gad.22417 0.113

86. Liu Z, Wang J, Cheng H, Ke X, Sun L, Zhang QC et al (2018) Cryo-EM structure of human dicer and its complexes with a premiRNA substrate. Cell 173:1549-1550. https://doi.org/10.1016/j. cell.2018.05.031

87. Louis D, Ohgaki K, Wiestler O, Cavenee W, Ellison D, FigarellaBranger D (2016) WHO classification of tumours of the central nervous system, 4th edn. IARC, Lyon (978-92-832-4492-9)

88. Louis DN, Ohgaki H, Wiestler OD, Cavenee WK, Burger PC, Jouvet A et al (2007) The 2007 WHO classification of tumours of the central nervous system. Acta Neuropathol 114:97-109. https://doi.org/10.1007/s00401-007-0243-4

89. Louis DN, Perry A, Reifenberger G, von Deimling A, Figarella-Branger D, Cavenee WK (2016) The 2016 World Health Organization classification of tumors of the central nervous system: a summary. Acta Neuropathol 131:803-820. https://doi. org/10.1007/s00401-016-1545-1

90. Lozier AM, Rich ME, Grawe AP, Peck AS, Zhao P, Chang AT et al (2015) Targeting ornithine decarboxylase reverses the LIN28/Let-7 axis and inhibits glycolytic metabolism in 
neuroblastoma. Oncotarget 6:196-206. https://doi.org/10.18632 /oncotarget. 2768

91. Malnou EC, Umlauf D, Mouysset M, Cavaille J (2018) Imprinted microRNA gene clusters in the evolution, development, and functions of mammalian placenta. Front Genet 9:706. https://doi. org/10.3389/fgene.2018.00706

92. Manjila S, Ray A, Hu Y, Cai DX, Cohen ML, Cohen AR (2011) Embryonal tumors with abundant neuropil and true rosettes: 2 illustrative cases and a review of the literature. Neurosurg Focus 30:E2. https://doi.org/10.3171/2010.10.FOCUS10226

93. Mayr C, Hemann MT, Bartel DP (2007) Disrupting the pairing between let-7 and Hmga2 enhances oncogenic transformation. Science 315:1576-1579. https://doi.org/10.1126/science.11379 99

94. Mogilyansky E, Rigoutsos I (2013) The miR-17/92 cluster: a comprehensive update on its genomics, genetics, functions and increasingly important and numerous roles in health and disease. Cell Death Differ 20:1603-1614. https://doi.org/10.1038/ cdd. 2013.125

95. Molenaar JJ, Domingo-Fernandez R, Ebus ME, Lindner S, Koster J, Drabek K et al (2012) LIN28B induces neuroblastoma and enhances MYCN levels via let-7 suppression. Nat Genet 44:1199-1206. https://doi.org/10.1038/ng.2436

96. Mong EF, Yang Y, Akat KM, Canfield J, VanWye J, Lockhart $\mathrm{J}$ et al (2020) Chromosome 19 microRNA cluster enhances cell reprogramming by inhibiting epithelial-to-mesenchymal transition. Sci Rep 10:3029. https://doi.org/10.1038/s4159 8-020-59812-8

97. Munji RN, Choe Y, Li G, Siegenthaler JA, Pleasure SJ (2011) Wnt signaling regulates neuronal differentiation of cortical intermediate progenitors. J Neurosci 31:1676-1687. https:// doi.org/10.1523/JNEUROSCI.5404-10.2011

98. Neumann JE, Wefers AK, Lambo S, Bianchi E, Bockstaller M, Dorostkar MM et al (2017) A mouse model for embryonal tumors with multilayered rosettes uncovers the therapeutic potential of Sonic-hedgehog inhibitors. Nat Med 23:11911202. https://doi.org/10.1038/nm.4402

99. Nguyen PNN, Choo KB, Huang CJ, Sugii S, Cheong SK, Kamarul T (2017) miR-524-5p of the primate-specific C19MC miRNA cluster targets TP53IPN1- and EMT-associated genes to regulate cellular reprogramming. Stem Cell Res Ther 8:214. https://doi.org/10.1186/s13287-017-0666-3

100. Nishino J, Kim I, Chada K, Morrison SJ (2008) Hmga2 promotes neural stem cell self-renewal in young but not old mice by reducing p16Ink4a and p19Arf expression. Cell 135:227239. https://doi.org/10.1016/j.cell.2008.09.017

101. Noguer-Dance M, Abu-Amero S, Al-Khtib M, Lefevre A, Coullin P, Moore GE et al (2010) The primate-specific microRNA gene cluster (C19MC) is imprinted in the placenta. Hum Mol Genet 19:3566-3582. https://doi.org/10.1093/hmg/ddq27 2

102. Nowak J, Seidel C, Berg F, Pietsch T, Friedrich C, von Hoff K et al (2014) MRI characteristics of ependymoblastoma: results from 22 centrally reviewed cases. AJNR Am J Neuroradiol 35:1996-2001. https://doi.org/10.3174/ajnr.A4002

103. Nowak J, Seidel C, Pietsch T, Alkonyi B, Fuss TL, Friedrich C et al (2015) Systematic comparison of MRI findings in pediatric ependymoblastoma with ependymoma and CNS primitive neuroectodermal tumor not otherwise specified. Neuro-oncology 17:1157-1165. https://doi.org/10.1093/neuonc/nov063

104. Okada C, Yamashita E, Lee SJ, Shibata S, Katahira J, Nakagawa A et al (2009) A high-resolution structure of the pre-microRNA nuclear export machinery. Science 326:1275-1279. https://doi. org/10.1126/science.1178705

105. Omari Y, Karkash AA, Mansour RA, Amayiri N, Swaidan M, Al-Hussaini M (2019) Medulloepithelioma with heterologous osteoid component: a case report and review of literature. Childs Nerv Syst 35:1035-1039. https://doi.org/10.1007/s00381-01804041-8

106. Ostrom QT, Cioffi G, Gittleman H, Patil N, Waite K, Kruchko $\mathrm{C}$ et al (2019) CBTRUS statistical report: primary brain and other central nervous system tumors diagnosed in the United States in 2012-2016. Neuro-oncology 21:v1-v100. https://doi. org/10.1093/neuonc/noz150

107. Patterson M, Gaeta X, Loo K, Edwards M, Smale S, Cinkornpumin $\mathrm{J}$ et al (2014) let-7 miRNAs can act through notch to regulate human gliogenesis. Stem Cell Rep 3:758-773. https:// doi.org/10.1016/j.stemcr.2014.08.015

108. Pei Y, Brun SN, Markant SL, Lento W, Gibson P, Taketo MM et al (2012) WNT signaling increases proliferation and impairs differentiation of stem cells in the developing cerebellum. Development 139:1724-1733. https://doi.org/10.1242/dev.050104

109. Pfaff E, Aichmuller C, Sill M, Stichel D, Snuderl M, Karajannis MA et al (2020) Molecular subgrouping of primary pineal parenchymal tumors reveals distinct subtypes correlated with clinical parameters and genetic alterations. Acta Neuropathol 139:243-257. https://doi.org/10.1007/s00401-019-02101-0

110. Pfister S, Remke M, Castoldi M, Bai AH, Muckenthaler MU, Kulozik A et al (2009) Novel genomic amplification targeting the microRNA cluster at 19q13.42 in a pediatric embryonal tumor with abundant neuropil and true rosettes. Acta Neuropathol 117:457-464. https://doi.org/10.1007/s00401-008-0467-y

111. Place RF, Li LC, Pookot D, Noonan EJ, Dahiya R (2008) MicroRNA-373 induces expression of genes with complementary promoter sequences. Proc Natl Acad Sci USA 105:1608-1613. https ://doi.org/10.1073/pnas.0707594105

112. Powers JT, Tsanov KM, Pearson DS, Roels F, Spina CS, Ebright $\mathrm{R}$ et al (2016) Multiple mechanisms disrupt the let-7 microRNA family in neuroblastoma. Nature 535:246-251. https://doi. org/10.1038/nature18632

113. Rakheja D, Chen KS, Liu Y, Shukla AA, Schmid V, Chang TC et al (2014) Somatic mutations in DROSHA and DICER1 impair microRNA biogenesis through distinct mechanisms in Wilms tumours. Nat Commun 2:4802. https://doi.org/10.1038/ncomm s5802

114. Rao S, Rajeswarie RT, Chickabasaviah Yasha T, Nandeesh BN, Arivazhagan A, Santosh V (2017) LIN28A, a sensitive immunohistochemical marker for Embryonal Tumor with Multilayered Rosettes (ETMR), is also positive in a subset of Atypical Teratoid/Rhabdoid Tumor (AT/RT). Childs Nerv Syst 33:1953-1959. https://doi.org/10.1007/s00381-017-3551-6

115. Rausch T, Jones DT, Zapatka M, Stutz AM, Zichner T, Weischenfeldt J et al (2012) Genome sequencing of pediatric medulloblastoma links catastrophic DNA rearrangements with TP53 mutations. Cell 148:59-71. https://doi.org/10.1016/j.cell.2011.12.013

116. Santos-Pereira JM, Aguilera A (2015) R loops: new modulators of genome dynamics and function. Nat Rev Genet 16:583-597. https://doi.org/10.1038/nrg3961

117. Schmidt C, Schubert NA, Brabetz S, Mack N, Schwalm B, Chan JA (2017) Preclinical drug screen reveals topotecan, actinomycin D, and volasertib as potential new therapeutic candidates for ETMR brain tumor patients. Neuro Oncol 19:1607-1617. https ://doi.org/10.1093/neuonc/nox093

118. Schnepp RW, Khurana P, Attiyeh EF, Raman P, Chodosh SE, Oldridge DA (2015) A LIN28B-RAN-AURKA signaling network promotes neuroblastoma tumorigenesis. Cancer Cell 28:599-609. https://doi.org/10.1016/j.ccell.2015.09.012

119. Shah AH, Khatib Z, Niazi T (2018) Extracranial extra-CNS spread of embryonal tumor with multilayered rosettes (ETMR): case series and systematic review. Childs Nerv Syst 34:649-654. https://doi.org/10.1007/s00381-017-3657-x 
120. Sin-Chan P, Mumal I, Suwal T, Ho B, Fan X, Singh I et al (2019) A C19MC-LIN28A-MYCN oncogenic circuit driven by hijacked super-enhancers is a distinct therapeutic vulnerability in ETMRs: a lethal brain tumor. Cancer Cell 36(51-67):e57. https://doi. org/10.1016/j.ccell.2019.06.002

121. Singh I, Mehta A, Contreras A, Boettger T, Carraro G, Wheeler $M$ et al (2014) Hmga2 is required for canonical WNT signaling during lung development. BMC Biol 12:21. https://doi. org/10.1186/1741-7007-12-21

122. Skourti-Stathaki K, Kamieniarz-Gdula K, Proudfoot NJ (2014) R-loops induce repressive chromatin marks over mammalian gene terminators. Nature 516:436-439. https://doi.org/10.1038/ nature 13787

123. Spence T, Perotti C, Sin-Chan P, Picard D, Wu W, Singh A et al (2014) A novel C19MC amplified cell line links Lin28/let-7 to mTOR signaling in embryonal tumor with multilayered rosettes. Neuro Oncol 16:62-71. https://doi.org/10.1093/neuonc/not162

124. Spence T, Sin-Chan P, Picard D, Barszczyk M, Hoss K, Lu M et al (2014) CNS-PNETs with C19MC amplification and/or LIN28 expression comprise a distinct histogenetic diagnostic and therapeutic entity. Acta Neuropathol 128:291-303. https:// doi.org/10.1007/s00401-014-1291-1

125. Stefaniuk M, Swiech L, Dzwonek J, Lukasiuk K (2010) Expression of Ttyh1, a member of the Tweety family in neurons in vitro and in vivo and its potential role in brain pathology. J Neurochem 115:1183-1194. https://doi.org/10.1111/j.1471-4159.2010.07023 . $\mathrm{x}$

126. Sturm D, Orr BA, Toprak UH, Hovestadt V, Jones DTW, Capper $D$ et al (2016) New brain tumor entities emerge from molecular classification of CNS-PNETs. Cell 164:1060-1072. https://doi. org/10.1016/j.cell.2016.01.015

127. Swahari V, Nakamura A, Baran-Gale J, Garcia I, Crowther AJ, Sons $\mathrm{R}$ et al (2016) Essential function of dicer in resolving DNA damage in the rapidly dividing cells of the developing and malignant cerebellum. Cell Rep 14:216-224. https://doi.org/10.1016/j. celrep.2015.12.037

128. Torrezan GT, Ferreira EN, Nakahata AM, Barros BD, Castro MT, Correa BR et al (2014) Recurrent somatic mutation in DROSHA induces microRNA profile changes in Wilms tumour. Nat Commun 5:4039. https://doi.org/10.1038/ncomms5039

129. Uro-Coste E, Masliah-Planchon J, Siegfried A, Blanluet M, Lambo S, Kool M et al (2019) ETMR-like infantile cerebellar embryonal tumors in the extended morphologic spectrum of DICER1-related tumors. Acta Neuropathol 137:175-177. https ://doi.org/10.1007/s00401-018-1935-7

130. Vaira V, Elli F, Forno I, Guarnieri V, Verdelli C, Ferrero S et al (2012) The microRNA cluster C19MC is deregulated in parathyroid tumours. J Mol Endocrinol 49:115-124. https://doi. org/10.1530/JME-11-0189

131. Van Poppel M, Klimo P Jr, Dewire M, Sanford RA, Boop F, Broniscer A et al (2011) Resection of infantile brain tumors after neoadjuvant chemotherapy: the St. Jude experience. J Neurosurg Pediatr 8:251-256. https://doi.org/10.3171/2011.6.Peds11158

132. Vasudevan S, Tong Y, Steitz JA (2007) Switching from repression to activation: microRNAs can up-regulate translation. Science 318:1931-1934. https://doi.org/10.1126/science.1149460

133. Vedanayagam J, Chatila WK, Aksoy BA, Majumdar S, Skanderup AJ, Demir E et al (2019) Cancer-associated mutations in DICER1 RNase IIIa and IIIb domains exert similar effects on miRNA biogenesis. Nat Commun 10:3682. https:// doi.org/10.1038/s41467-019-11610-1

134. Viswanathan SR, Powers JT, Einhorn W, Hoshida Y, Ng TL, Toffanin $\mathrm{S}$ et al (2009) Lin28 promotes transformation and is associated with advanced human malignancies. Nat Genet 41:843-848. https://doi.org/10.1038/ng.392
135. Walz AL, Ooms A, Gadd S, Gerhard DS, Smith MA, Guidry Auvil JM et al (2015) Recurrent DGCR8, DROSHA, and SIX homeodomain mutations in favorable histology Wilms tumors. Cancer Cell 27:286-297. https://doi.org/10.1016/j.ccell 2015.01 .003

136. Wang B, Gogia B, Fuller GN, Ketonen LM (2018) Embryonal tumor with multilayered rosettes, C19MC-altered: clinical, pathological, and neuroimaging findings. J Neuroimaging 28:483-489. https://doi.org/10.1111/jon.12524

137. Wang HW, Noland C, Siridechadilok B, Taylor DW, Ma E, Felderer K et al (2009) Structural insights into RNA processing by the human RISC-loading complex. Nat Struct Mol Biol 16:1148-1153. https://doi.org/10.1038/nsmb.1673

138. Wang Y, Chen J, Yang W, Mo F, Senz J, Yap D et al (2015) The oncogenic roles of DICER1 RNase IIIb domain mutations in ovarian Sertoli-Leydig cell tumors. Neoplasia 17:650-660. https ://doi.org/10.1016/j.neo.2015.08.003

139. Wefers AK, Lindner S, Schulte JH, Schuller U (2017) Overexpression of Lin28b in neural stem cells is insufficient for brain tumor formation, but induces pathological lobulation of the developing cerebellum. Cerebellum 16:122-131. https://doi. org/10.1007/s12311-016-0774-0

140. Wend P, Runke S, Wend K, Anchondo B, Yesayan M, Jardon $M$ et al (2013) WNT10B/beta-catenin signalling induces HMGA2 and proliferation in metastatic triple-negative breast cancer. EMBO Mol Med 5:264-279. https://doi.org/10.1002/ emmm.201201320

141. Wiernasz E, Kaliszewska A, Brutkowski W, Bednarczyk J, Gorniak M, Kaza B et al (2014) Ttyh1 protein is expressed in glia in vitro and shows elevated expression in activated astrocytes following status epilepticus. Neurochem Res 39:2516-2526. https ://doi.org/10.1007/s11064-014-1455-3

142. Wu G, Xu G, Schulman BA, Jeffrey PD, Harper JW, Pavletich NP (2003) Structure of a beta-TrCP1-Skp1-beta-catenin complex: destruction motif binding and lysine specificity of the SCF(betaTrCP1) ubiquitin ligase. Mol Cell 11:1445-1456. https://doi. org/10.1016/s1097-2765(03)00234-X

143. Wu HN, Cao XL, Fang Z, Zhang YF, Han WJ, Yue KY et al (2019) Deficiency of Ttyh1 downstream to Notch signaling results in precocious differentiation of neural stem cells. Biochem Biophys Res Commun 514:842-847. https://doi.org/10.1016/j. bbrc.2019.04.181

144. Xie L, Mouillet JF, Chu T, Parks WT, Sadovsky E, Knofler $\mathrm{M}$ et al (2014) C19MC microRNAs regulate the migration of human trophoblasts. Endocrinology 155:4975-4985. https://doi. org/10.1210/en.2014-1501

145. Yang X, Lin X, Zhong X, Kaur S, Li N, Liang S et al (2010) Double-negative feedback loop between reprogramming factor LIN28 and microRNA let-7 regulates aldehyde dehydrogenase 1-positive cancer stem cells. Cancer Res 70:9463-9472. https:// doi.org/10.1158/0008-5472.CAN-10-2388

146. Zaratiegui M, Castel SE, Irvine DV, Kloc A, Ren J, Li F et al (2011) RNAi promotes heterochromatic silencing through replication-coupled release of RNA Pol II. Nature 479:135-138. https ://doi.org/10.1038/nature10501

147. Zhang M, Muralimanoharan S, Wortman AC, Mendelson CR (2016) Primate-specific miR-515 family members inhibit key genes in human trophoblast differentiation and are upregulated in preeclampsia. Proc Natl Acad Sci USA 113:E7069-E7076. https://doi.org/10.1073/pnas.1607849113

148. Zhang X, Wan G, Berger FG, He X, Lu X (2011) The ATM kinase induces microRNA biogenesis in the DNA damage response. Mol Cell 41:371-383. https://doi.org/10.1016/j.molce 1.2011 .01 .020 
149. Zhou J, Ng SB, Chng WJ (2013) LIN28/LIN28B: an emerging oncogenic driver in cancer stem cells. Int J Biochem Cell Biol 45:973-978. https://doi.org/10.1016/j.biocel.2013.02.006

150. Zhu H, Shyh-Chang N, Segre AV, Shinoda G, Shah SP, Einhorn WS et al (2011) The Lin28/let-7 axis regulates glucose metabolism. Cell 147:81-94. https://doi.org/10.1016/j.cell.2011.08.033
Publisher's Note Springer Nature remains neutral with regard to jurisdictional claims in published maps and institutional affiliations. 